\title{
"Comentarios críticos a las teorias del desarrollo predominantes. Hacia otro concepto del desarrollo de las sociedades".
}

\author{
Roberto Rubio Fabian
}

\section{Introduccion}

Hoy, más que en otros tiempos, es época de cambios. La micro física viene mostrándonos que áun la realidad más sólida e "inamovible" está en constante renovación y es todos los dias, a cada segundo, una realidad nueva y diferente. Nuestras concepciones del universo, del tiempo y del espacio, de la naturaleza, del "bien y el mal", de la evolución de las sociedades, etc., se encuentran en constante y rápida transformación.

Las realidades sociales nunca habian presentado tanta "efervecencia" y generado tanta perplejidad: las "burbujas" de la perestroika alcanzaron los Estados más "paquidermicos" de la que todavia se llama Europa del Este; el pals imperial que con orgullo y cierta holgura financiaba la seguridad mundial de Occidente tuvo que salir en busca de "limosna" para sostener su presencia en El Golfo; "el comunismo" ya no amenaza "el mundo libre", al contrario éste apadrina el "rebautizo" de aquél y, al menos en Europa, busca el nuevo nombre que los propios partidos comunistas no se encuentran; en Latinoamérica gobiernos revolucionarios que se ganaron con las armas se pierden con los votos (ver Nicaragua), y "gobiernos democráticos" que se ganaron con los votos, para no perderse, se sostienen más que nunca en la institucionalidad armada (ver Guatemala y El Salvador), o tienen que perder "el poder de las armas" (ver los casos diferentes de los paises del Cono Sur). 
Hoy más que nunca cobra validez aquel pensamiento del clásico filósofo griego Heráclito, que decía que "lo único que realmente existe es el cambio".

Las "verdades", no se escapan de ese torbellino que destruye y reconstruye los más fuertes pilares sobre los que se edifican actualmente nuestras ciencias y nuestras religiones. Es dentro de tal contexto que la "verdad del desarrollo económico" viene siendo cuestionada desde hace ya varios años. De tal forma que si en un principio se comenzó poniendo en duda la premisa de que el desarrollo era igual al crecimiento económico, hoy se va más lejos al negar su identidad con un proceso acelerado de industrialización. En efecto, demasiados eran y siguen siendo los males surgidos de este proceso como para que no se alzaran voces pidiendo retirarlo del Olimpo. Así, dentro de las más variadas disciplinas muchas personas se fueron dando cuenta que, como diría Shakespeare, "habian más cosas en el cielo y en la tierra que nuestra filosofia", y que crecimiento e industrialización no definian por sí sólo el desarrollo.... habia muchas cosas más.

El interés y la inquietud por conocer esas "muchas otras cosas" introdujeron este trabajo en la senda de la crítica a las teorias del desarrollo. predominantes, como paso previo a la formulación de un concepto de desarrollo alternativo. En efecto, encaminarse hacia "otro" concepto del desarrollo de las sociedades, implicaba comenzar cuestionado "las verdades del desarrollo" imperante.

En base a lo anterior, la primera parte del trabajo se convierte en el objeto principal de estudio. En ella se lleva a cabo un análisis crítico de las más importantes teorias del desarrollo aparecidas luego de la segunda guerra mundial. Las concepciones rechazadas y los aportes que surgen del análisis crítico a las teorias del desarrollo predominantes, junto con las nuevas ideas del desarrollo (que provienen de teorias del desarrollo que podriamos denominar como alternativas) nos permitirán, en la segunda parte del trabajo, proponer algunos lineamientos básicos de lo que deberia contener una concepción diferente del desarrollo.

Valga aclarar que los lineamientos propuestos en la segunda parte tienen un carácter general e introductorio (de ahi nuestro sub-título "Hacia otro concepto del desarrollo de las sociedades"). Por tanto, se presume que se trata de lineamientos globales que servirán como base introductoria a la elaboración posterior de otro trabajo, en el cual se pretenderá llegar a propuestas de desarrollo alternativo más concretas, proposiciones que podrian volver operativo nuestro imaginario.

Esperamos que los análisis, valoraciones y conclusiones que expon- 
dremos en este documento sean un aporte al necesario proceso de cambio de las estructuras que han conducido a niveles degradante $e$ impensables las condiciones de vida de la mayoria de salvadoreños. Esperamos que sirvan en el avance de las estrategias y políticas que deben ser impulsadas e inventadas para sustituir con eficacia tales nocivas estructuras.

\section{Primera parte}

\section{Las teorías del desarrollo predominantes}

Existen varios criterios válidos para clasificar las diversas teorias del desarrollo. Por ejemplo se pueden colocar de acuerdo a su postura frente al desarrollo del capitalismo y tendremos así teorias clasificadas como continuistas, reformistas, rupturistas o radicales. Podemos distribuirlas respecto al instrumental teórico empleado y hablaremos entonces de teorias de inspiración clásica o neo clásica, marxista o neo marxista, keynesiana o neo keynesiana, etc. $Y$ si consideramos su metodología podremos precisarlas como marginalistas, funcionalistas, estructuralistas, etc.

Acá vamos a separar las diversas teorias del desarrollo predominantes según sus diferentes concepciones del desarrollo. Su presentación y análisis han sido en buena medida fundamentados en algunos estudios que versan sobre el tema en cuestión. ${ }^{2}$ Para la mayoria de estos trabajos las teorias del desarrollo más relevantes participan, a pesar de sus grandes diferencias, de una idea común: han asimilado la noción de desarrollo a la de proceso acelerado de industrialización, y la de éste a la de modernización. Y ella la comparten tanto las corrientes liberales y/o neo-clásicas como marxistas y/o estructuralistas, los partidarios del "desarrollo hacia afuera" como los del "desarrollo hacia adentro", los defensores del desarrollo del capitalismo como muchos de los promotores del desarrollo del socialismo. Todas son pues en el fondo Teorias de la Modernización. En todas ellas, por ejemplo los defectos o deformaciones de la agricultura, sean conyunturales o pasajeros para unos o perma-

2. Entre ellos destacamos: $L$ 'Histoire Ambigüe. Croissance et développement en question. de Pierre Dockes y Bernard Rosier; Accumulation et Développement de Marc Raffinot y Pierre Jacquemot; El sistema agroalimentario. Una visión integral de la cuestión agraria en América Latina, de Absalón Machado y Jorge Torres; Clés pour une strategie nouvelle du développement, de Bernard Rosier; Le potentiel de développement endogène, y Stratégies d'écodéveloppement de Ignace Sachs; Industialisation et Développement: la crise des paradigmes, de Claude Courlet y Pierre Judet. 
nentes para otros, son vistos e interpretados como simples obstáculos a la industrialización y al logro de la modemidad.

\section{Preclsemos algunos rasgos comunes a las teorlas del desarrollo. Predominantes.}

a. Poseen una visión "nupturista" del desarrollo. Es decir que la entrada en un proceso de industrialización/modernización implica una nuptura o corte con un pasado tradicional y arcaico, un "despegue" a partir del cual se obtendría la rápida expansión de las fuerzas productivas. En la versión liberal se pondria como ejemplo el "take-off" de Rostow. En la visión radical (Teoria de la Dependencia y/o marxismo) contemplariamos la "liberalización de las fuerzas productivas".

b. El desarrollo es concebido dentro de una trayectoria a seguir por etapas. Nuevamente aparece Rostow y sus cinco etapas del crecimiento del lado de la corriente liberal. Mientras que en los estructuralistas vinculados a la teoria de la dependencia se expresaria en las etapas a seguir en el proceso de sustitución de importaciones (que va desde los bienes de consumo no duradero hasta la sustitución de bienes de capital). En varios postulados marxistas las "leyes secuenciales e inevitables" de la concepción ortodoxa del materialismo histórico darian también prueba de su visión etapista del desarrollo.

c. La industrialización es percibida como un "proceso centrífugo". (Courlet y Judet) que irradia el desarrollo. De ahi la necesidad de creación de "polos de crecimiento". $Y$ aunque esta noción del "crecimiento transmitido" tiene su origen en el seno del liberalismo, la corriente radical participa de ella en la medida que limita su crítica a los mecanismos del mercado que crean tales polos en forma distorsionada y no incluya el cuestionamiento de la existencia de los polos como tales. De ahi que dentro de la corriente radical encontramos con frecuencia solamente recomendaciones para una intervención estatal que rehabilite o corrija las distorsiones de los polos creados.

d. En los estudios del desarrollo predominantes los paises dominados atrasados para unos y periféricos o dependientes para otros, son presentados como un todo más o menos homogéneo, desprovisto de diferencias significativas. "Sociedades arcaicas y rebeldes al progreso técnico" en un caso, "periféricas proletarizadas y rebeldes al progreso imperialismo" en los otros casos. "Regiones atrasadas y Ter-

3. COURLET, Claude y JUDET, Pierre. Industrialisation, et développement: la crise des paradigmes. Revue Tiers-Monde. No. 107. Julio-Sept. Paris. Pag. 526. 
cer Mundo son presentados como un conjunto indiferenciado, sin mayor margen de maniobra real en el movimiento de reproducción de las religiones internacionales". ${ }^{3}$ Valga acá reflexionar en el peso excesivo que la mayorla de investigaciones de la Teoria de la Dependencia dieron a los factores internacionales en detrimento del estudio de los fenómenos internos, a tal punto que los paises periféricos aparecian como meros sub-productos de los paises centrales.

e. Se caracterizan por una fatta de cuestionamiento o de análisis sobre el tipo de industrialización o sobre el tipo de desarrollo de las fuerzas productivas. Es decir que las teorias de la modernización conciben el desarrollo como el logro de un proceso unidimensional de industrialización: desarrollarse conlleva el contar con unas técnicas modemas que permitan el incremento o consolidación de un también moderno aparato productivo, que produzca en abundancia unos bienes (también modernos) que tiendan a satisfacer las necesidades ya sea de la población y/o de los capitalistas en particular. Es decir un tipo (y sólo uno) de industrialización. No se contempla por tanto el supuesto de un abanico de posibilidades técnicas (muchas de ellas no modernas), ni la conformación de un aparato productivo que produzca unos bienes diferentes, que no sólo se valoren por los mecanismos del mercado o por las instancias de planificación. Bienes que quizá no sean tan modernos pero si de una calidad que contribuya sensiblemente en el mejoramiento de las formas de vida de las poblaciones.

Creemos que algunas críticas surgidas desde dentro de la teoria de la dependencia respecto a la priorización de los bienes de lujo en el proceso de sustitución de importaciones, o al uso de técnicas importadas intensivas en capital y sus secuelas de dependencia, no permiten afirmar que dicha teoria se plantee otras nociones o dimensiones diferentes del desarrollo o de la industrialización. Es por ello que B. Rosier, cuando comenta críticamente el marxismo vinculado a la teoría de la dependencia, se refiere a la misma como economista, y le achaca su determinismo tecnológico; y ello lo lleva a oponer la noción marxista de "nivel $\mathrm{N}^{2}$ desarrollo de las fuerzas productivas a la noción de "tipo de desarrollo de las fuerzas productivas", la cual "se distingue radicalmente de las aproximaciones estrictamente cuantitativas (en términos de "nivel" de desarrollo de las fuerzas productivas o de tasa de crecimiento) por alcanzar el contenido preciso que encierran las fuerzas del desarrollo". ${ }^{4}$

f. Por último, la idea de desarrollo contenida en la teoria de la moderni-

4. ROSIER, Bernard. Clés pour une stratégie nouvelle du développement. UNESCO. Les Editions Ouvrières. Paris 1984. Pág. 116. 
zación hace prácticamente caso omiso de las relaciones del hombre con la naturaleza. El proceso de industrialización-modernización se lleva a cabo como si el ecosistema que to rodea fuera una realidad ajena y exógena. Las interrelaciones de aquel proceso con la naturaleza son, a lo sumo, relegadas a un segundo plano. De ahi el surgimiento, en parte, de los graves problemas ecológicos causados por la industrialización acelerada, ya sea en los paises capitalistas o en los paises llamados del socialismo real.

Expuestas algunas características comúnes de las teorias de la modemización pasemos a ver éstas con más detalle.

\section{Las teorias del crecimlento}

Dentro de las teorias de la modernización podremos distinguir dos grandes grupos: por un lado, las teorias del crecimiento, y por el otro, las teorias del desarrollo propiamente dichas o teorias del desarrollo/ modernización.

Las teorias del crecimiento, en términos generales.

a) No son teorias del desarrollo como tales por cuanto el subdesarrollo no aparece como objeto de estudio. "Por sus mismos presupuestos, ella no propone ningún análisis propio del fenómeno del "desarrollo": estando simplemente "en retraso" los paises "subdesarrollados" están solamente invitados a seguir la "vía real" que han trazado, para ellos, los paises desarrollados. Uno se remite a la sola teoria del crecimiento"5.

b) Es una teoria cuya concepción de desarrollo se reduce sólo a aquellas variables económicas que permiten el crecimiento. Las teorias del desarrollo modernización, sin embargo sí tienen como objeto específico de estudio la problemática del "subdesarrollo" e introducen al análisis variables no estrictamente económicas. Realizamos primeramente una somera presentación de las teorias del crecimiento.

\subsection{Rasgos generales}

a. Estas teorias poseen una noción del desarrollo que lleva a ubicar a los paises subdesarrollados como simple retraso respecto a to ya conseguido por los paises industrializados. Se trata sólo de proseguir una senda ya recorrida. En tal sentido los paises atrasados no poseen historia propia (J. P. Peemans) y su dinámica se define en torno a las posibilidades de "atrapar" los logros de la industrialización. En

5. ROSIER, Bernard. Op. cit. Pág. 103. 
tal contexto los paises atrasados, o regiones de lo mismos, son contemplados como sociedades tradicionales que bloquean la modernidad. Es por tanto una noción dualista funcional, en la medida que sólo existen dos sectores, uno de los cuales, el tradicional, debe ser "destruido" o "convertido" a la modernidad por medio de la eliminación de los obstáculos que impiden "su progreso". El contenido de las políticas económicas se limita entonces a actuar sobre aquellas variables económicas que frenan el crecimiento, es decir la transformación del sector tradicional en moderno. $Y$ ese proceso de destrucción-transformación se realiza (debe realizarse) por etapas bien definidas. Lo cual se debe dar no sólo a nivel económico, como las cinco etapas de Rostow (Sociedad tradicional-transición-despegue-etapa de madurez-era del consumo intensivo o del consumo de masas) sino también, a un nivel más global, ya que la madurez económica lleva luego a la madurez social y posteriormente a la política. Se trata asimismo de un modelo de crecimiento que posee un carácter universal, es decir un modelo alcanzable e imitable por todos los paises. ${ }^{6}$ Caracteristicas generales de la teoria del crecimiento son pues, su visión líneal del subdesarrollo como simple retraso, su enfoque dualista funcional, su economismo, evolucionismo y universalismo.

b) Es preciso indicar,que los modelos de crecimiento están determinados por las condiciones históricas de su época. Son teorias que surgen inmediatamente después de finalizada la segunda guerra mundial (su impulso data de 1945 a 1965 aproximadamente, aunque su momento de más fuerza se ubica entre 1945-55). Es un periodo de post-guerra marcado por una fuerte expansión económica, sobre todo en los Estados Unidos, y que conlleva toda la actividad de reconstrucción de una Europa devastada por la guerra, abrigada y dinamizada por el Plan Marshall. Abarca también una época de "descubrimiento" del Sur de Europa (Sur de Francia, de Espana, de Italia, Portugal, Grecia, Bulgaria, Rumania) y de la necesidad de lograr su crecimiento económico e integración nacional. De la misma forma comprendia un contexto de "guerra fria" y un periodo de descolonización (sobre todo en el Africa) que hacia surgir nuevos paises políticamente independientes, pero llenos de dificutades económicas y desprovistos de vias alternativas para enfrentarlas. En tal marco, era preciso hacer crecer económicamente a estos paises, y permitir al mismo tiempo articularlos internamente en vias de la construcción de

6. A la época se citaba con frecuencia al Japón como ejemplo de un país tradicional y culturalmente diferente, que si habia podido entrar en la ruta de la modernidad era gracias a la universalidad de ésta. 
un verdadero Estado-Nación. Todo lo cual los alejaría de las experiencias de desarrollo exhibidas por los paises comunistas. ${ }^{7}$

El "boom" del crecimiento económico en los paises industrializados, su necesidad de explicación y control, asi como los requerimientos de transmitr esa experiencia a los paises atrasados, fueron, en conclusión, los factores que posibilitan también el "boom" de las teorias del crecimiento.

c. En consecuencia son teorias que se presentan como una reflexión del Norte sobre si mismo (Peemans). Una reflexión sobre las formas de garantizar el control o continuación del crecimiento.

Teniendo en cuenta los hechos pasados (como los problemas cíclicos de la dinámica económica y los obstáculos que surgen de la sobreproducción, sobre todo ocurridos durante la crisis de los anos 30 ) las teorias del crecimiento centraron sus esfuerzos en buscar los mecanismos que garantizaran el crecimiento equilibrado. Esto explica en parte por qué la mayoria de los modelos de crecimiento tuvieron una inspiración Keynesiana. Cientamente Keynes no formulaba una teoria del crecimiento sino más bien una teoria del equilibrio, es decir de las condiciones que permitlan el funcionamiento de una economia desarrollada (y no tanto su crecimiento). Dicho equilibrio se manifiesta en la ecuación S = I (el ahorro global debería ser igual a la inversión global), y era posible gracias a que la inversión era generadora de ingresos y ajustaba los posibles desequilibrios de la economía por medio del efecto multiplicador. Pero en ese tipo de equilibrio (estático, a corto plazo y regulado ${ }^{8}$ se encontraron los fundamentos para luego postular un crecimiento equilibrado (dinámico, a largo plazo y también regulado) que logrará y garantizará la continuación de la modernidad.

Vistas las características generales pasemos a un análisis particular de las teorias del crecimiento.

\subsection{Rasgos de algunas teorías del crecimiento}

Trataremos de resumir ciertas características de los modelos de crecimiento, pertenecientes a relevantes exponentes de las teorias en estudio, durante el periodo 1945-1965.

7. No es casual que Rostow califique su obra como un "Manifiesto NoComunista".

8. Es decir que requiere de la intervención estatal, y expresa su desconfianza respecto al equilibrio automático de los sistemas de precios. 
a. Uno de los primeros en formular un modelode crecimiento equilibrado fue E. R. Domar con su obra "Capital expansion, rate of growth and employment" aparecida en abril de 1946 (y que significaba una continuación de los trabajos emprendidos por Harrod en 1939). El modelo Harrod-Domar, como se le conoce, buscaba establecer las condiciones que permitieron crecer en forma equilibrada y contínua una economia desarrollada. Consideraba, como en Keynes, que la condición de equilibrio principal era $S=1$. Pero en un contexto dinámico, la Inversión no sólo es generadora de ingresos sino que también se ve a su vez determinada por los mismos (no interviene solamente el efecto multiplicador sino también el "efecto acelerador"). En consecuencia, los mayores niveles de ingresos, correspondientes a los nuevos niveles de capital, pueden provocar desequilibrio en $S=I$. Para evitarlo habría que "actuar" en la construcción de otro equilibrio: la tasa de crecimiento del capital debe igualarse a la tasa de crecimiento de los ingresos, o sea $\Delta K / K=\Delta Y / y$. Este equilibrio, que requiere de una relación $\mathrm{k} / \mathrm{y}$ constante (llamada relación "capitaloutput"), se puede lograr si la economía creciera a una tasa que Domar llama "tasa garantizada" o g (donde $g$ debe ser igual a la propensión a consumir entre la relación capital-output). Siendo $\mathrm{k} / \mathrm{y}$ representada como q y la propensión a consumir como s, luego el equilibrio dinámico se obtendría con la ecuación $\mathrm{g}=\mathbf{s} / \mathbf{g}$.

Por tanto uno de los objetivos esenciales del modelo de Harrod y Domar es simplemente compatibilizar el crecimiento con la acumulación.

Su preocupación fundamenfal se encuentra en la búsqueda de una tasa garantizada ( $(9)$, ya que ésta justamente "garantiza" la industrialización, la modernización y por ende "el desarrollo". Lo más que este tipo de formulaciones llegan a recomendar a los paises sub-desarrollados es la necesidad, impostergable y urgente, de contar con un acervo suficiente de capital para emprenderse en la senda del crecimiento sostenido. Se comprende a partir de acá la otra recomendación que nace del modelo: la necesidad que los paises industrializados exporten capitales hacia los paises del Tercer Mundo y la conveniencia de cambiar los patrones de consumo y modos de vida "primitivos" (para conseguir las modificaciones en la propensión al consumo o "s").

9. Si la relación $k / y$ no fuera constante, por ejemplo si los incrementos de sobreproducción y el desempleo. $Y$ en caso contrario ( $\Delta Y$ son mayores a $\Delta K)$ surgirla la inflación. 
b. El modelo de crecimiento de R. M. Solow (en "Technical change and aggregate production function"), más próximo a los postulados neoclásicos, es también otro buen exponente de los teóricos del crecimiento. A pesar que su preocupación básica es la búsqueda de una tasa de crecimiento equilibrada, o la garantizada de Harrod-Domar, los mecanismos que propone para conseguirla son diferentes a la de éstos. Solow considera que los posibles efectos desequilibrantes que conlleva el crecimiento se corrigen automáticamente por medio de los mecanismos del mercado, y más concretamente a través de la dinámica de sustitución que se da entre los factores capital-trabajo. Para Solow, como en el modelo Harrod-Domar, el crecimiento implica un incremento del capital que conduce a la modificación del equilibrio entre la tasa de crecimiento del capital y la de los ingresos $(\Delta K / K$ deja de ser igual a $\Delta Y / y$ y eleva la relación $k / y$ que debe ser constante). Sin embargo, para Solow los desequilibrios son reestablecidos automáticamente por las variaciones que los mismos aumentos del capital provocan en las relaciones de sustitución que existen entre el capital y el trabajo (o en la relación $\mathrm{k} / \mathrm{t}$ ). De tal suerte que si la tasa de acumulación del capital fuera mayor que la tasa de crecimiento de la fuerza de trabajo, luego la relación k/t se modifica al alza, y ésta mayor abundancia relativa del capital sobre el factor trabajo conduce a su vez a una baja en el precio relativo del capital con relación al trabajo; lo que termina por traducir una mayor demanda del factor capital y por tanto en la mayor elevación de la relación $\mathrm{k} / \mathrm{y}$. $\mathrm{Y}$ son los aumentos de esta relación que van ir frenando el ritmo de crecimiento de la tasa de acumulación: los incrementos de dicha relación significan una menor "rentabilidad" del capital, una tendencia a invertir menos. Con lo cual la tasa de acumulación bajará y reestablecerá su equilibrio con la tasa de crecimiento de los ingresos. Como se notará, el modelo de Salow critica la rigidez del modelo Harrod-Domar: en la ecuación $g=s / q$, la relación capital-output (o la variable q) no tiene porque ser mantenida rígidamente para lograr el equilibrio. Al contrario, es una variable flexible cuya constancia es asegurada por los mecanismos del mercado de factores. Para Solow no es pues necesaria la intervención externa o estatal para obtener una relación k/y constante.

Las políticas de desarrollo que se desprenden de este modelo para los países del Tercer Mundo no pueden ser otras que aquellas sustentadas en el "laisser-faire" y en la necesidad de dinamización y liberación del comercio.

c. El llamado modelo de Kaldor-Robinson, de carácter neo-keynesiano, busca también el crecimiento equilibrado por medio del logro de la 
igualdad $S=I$ (Keynes) y del mantenimiento de la ecuación $\Delta K / K=$ $\Delta Y / y$ (Harrod-Domar). Como en Solow, considera que los incrementos del capital ocasionados por el crecimiento inducen cambios en la relación $k /$, sobre la relación $k / y$. Pero estas consideraciones no son suficientes ya que los aumentos del capital no sólo provocan cambios en las relaciones de $k / t$ (Solow), o en $\Delta K / K=\Delta y / y$ (Harrod-Domar), sino también en la distribución de los ingresos, entre los salarios y los beneficios. Podemos asi destacar cuatro planteamientos generales del modelo: 1) Las variaciones en la distribución de los ingresos producen transformaciones en la propensión a consumir. Por tanto la " $s$ " se modifica y aparece el desequilibrio que impide obtener la ecuación $g=s / q$. 2) Sin embargo, en un corto plazo puede haber equilibrio si reducimos el consumo a favor de la inversión. En efecto, contemplado desde el punto:de vista de los beneficios, el aumento del capital se traduce en un incremento de su oferta en detrimento de la oferta de bienes de consumo. Con lo que el precio de estos últimos se eleva, perjudicando el nivel de salarios reales pero favoreciendo el nivel de beneficios. $Y$ dado que se supone (en el modelo) que sólo los capitalistas tienen capacidad de ahorro, luego ello creará el nivel suficiente de éste para enfrentar los incrementos de capital. O sea que en definitiva los aumentos en la inversión generan los niveles de beneficio (ahorro) requeridos por la nueva escala de inversión, lográndose asi el equilibrio básico de $S=1$ de Keynes. 3) Pero resulta que a medio o largo plazo el equilibrio no se garantiza. Visto desde el punto de vista de los salarios, la reducción de su nivel real, y su efecto sobre la dinámica del mercado, tienden a frenar el proceso de acumulación y a provocar los desajustes que de ello se derivan. 4) De ahi que la única forma de conseguir un equilibrio a largo plazo, considerando las variaciones en la propensión al consumo y dentro de un proceso de crecimiento que conlleve mayores aumentos en los niveles de beneficios (de ahorros) sin afectar los salarios reales, es por medio del progreso técnico. ${ }^{10} \mathrm{El}$ excedente suplementario adquirido por este progreso permitiria mantener los salarios a su nivel anterior." De ahi que una de las principales recomendaciones

10. El modelo se refiere a cambios tecnológicos y no a cambios técnicos. Estos solamente expresan una modificación en las relaciones entre $k$ y $t$ sin que ello varie el producto (como lo planeaba Solow, es decir como simple sustituibilidad de factores). Mientras que el cambio tecnológico puede implicar mantener fija la relación $\mathrm{k} / \mathrm{t}$ e incrementarse el producto por medio de la "innovación técnica".

11. Como se notará todo ello requiere el mantenimiento de cierta tasa de rentabilidad del capital o de los beneficios y de cierto fomento del progreso técnico, lo que hace un llamado a la intervención estatal. 
que en materia de política económica se extraen del modelo KaldorRobinson es la colocación del progreso técnico como "motor" del desarrollo: desarrollarse es progresar técnicamente, modernizarse es innovación tecnológica permanente.

d. Finalmente tenemos otro modelo que, según sus métodos y concepciones, podremos ubicarlo también dentro de las teorias del crecimiento. Se trata del modelo de crecimiento elaborado por I. Adelman (expuesto en "A neo-Keynesian Model of a Growing Economy" 1961). Sin embargo valga aclarar que podemos calificarlo como un primer esbozo de las teorias del desarrollo/modernización en la medida que se introduce dentro del modelo una variable que no es estrictamente económica, como es el factor demográfico, y en la medida que su reflexión fundamental se dirige a "los paises subdesarrollados", donde la variable demográfica juega un rol preponderante. Este matiz es en buena parte comprensible si consideramos que el modelo de Adelman, posterior a los anteriores, se elabora en un periodo donde se deja sentir más el impacto de la descolonización y el surgimiento de los movimientos de liberación. Por tanto este modelo no sólo pretende establecer las condiciones del crecimiento equilibrado para una economia "desarrollada" (reflexión del Norte sobre si mismo) sino también para los paises "subdesarrollados" (reflexión del Norte sobre el Sur). Adelman introduce en su modelo la búsqueda de la tasa "g" que garantiza el crecimiento equilibrado y las necesarias condiciones de equilibrio que planteaban los modelos precedentes: $\Delta K / K=\Delta Y / y 0$ $k / y$ constante en Harrod-Domar, $k / t=k / y$ (con cambios tecnológicos) en Kaldor-Robinson. Pero anade un nuevo equilibrio: es menester que las anteriores igualdades se equiparen también con una determinada tasa de crecimiento de la población. La variable demográfica deja de ser entonces exógena al modelo y es determinada dentro del mismo. Determinación que viene dada de la siguiente manera: el crecimiento del capital no sólo induce variaciones entre los ingresos y las inversiones, o entre los factores de producción, o en la distribución de los ingresos entre los capitalistas y los asalariados, sino también en la tasa de crecimiento de la población ( $p$ ). $Y$ esto se da porque los incrementos del capital, al elevar la relación $\mathrm{k} / \mathrm{t}$, hace más escaza la fuerza de trabajo respecto al capital y por ende tiende a producir aumento en los salarios que favorecen un mayor crecimiento demográfico. ¿Cómo se efectua esto? en un primer momento (cuando el nivel de salario es o ha sido bajo) los mayores salarios se traducen en un incremento del ritmo de crecimiento de la población (ya que baja la tasa de mortalidad y se eleva la de natalidad). En consecuencia, el crecimiento económico al crear aumentos en la tasa 
de crecimiento de la población, se convierte en fuente de desequilibrio: los mayores contingentes poblacionales modifican las relaciones constantes de equilibrio de $\mathrm{k} / \mathrm{t}$ y de $\mathrm{y} / \mathrm{t}$. Ahora bien, esto puede ser reestablecido, en un segundo momento, cuando los incrementos salariales son tan altos que la tasa de crecimiento de la población deja de subir y tiende a estabilizarse (la reducción de la tasa de mortalidad tiene cierto límite y la "modernidad cultural" que acompanan los mayores niveles de vida hacen descender la tasa de natalidad, tal como ha sucedido en los paises industrializados). O sea que el equilibrio se establece cuando la tasa de crecimiento económico, o la tasa de acumulación, no sólo es igual a $k / y, k / t$ y y/t sino también a $P$, es decir, cuando iguala o llega a producir una tasa "estabilizada" de crecimiento de la población (P). En este marco, según Adelman el problema del subdesarrollo no se expresa tanto en las pocas posibilidades que existen de "llevar lejos" los niveles salariales sino en el hecho que las alzas de salario no llegan a producir una tasa "estabilizada" de crecimiento de la población. Esto debido, en buena medida, al "atraso cultural". De tal manera que, aún con progreso técnico, el incremento demográfico se "come" los excedentes suplementarios surgidos de él. Es pues una visión pesimista del desarrollo, impregnada de "malthusianismo", y que propohe como gran política de desarrollo la necesidad de reducir las tasas de crecimiento de la población como única salida posible del estado de atraso de los países del Tercer Mundo. De acá también surge la exigencia de la intervención estatal y sus políticas prioritarias sobre el control de la natalidad y de planificación familar.

En resumen, podremos haber notado que las teorias del crecimiento expuestas reducen el concepto de desarrollo al de crecimiento/acumulación equilibrada. Es una reducción del complejo problema del desarrollo a la fria simplicidad de las cifras macroeconómicas elementales: el desarrollo medible y valorable por los "números per-cápita". Sus preocupaciones esenciales residen en la formalización de un modelo que establezca las condiciones de un crecimiento equilibrado y los mecanismos para lograrlo. ${ }^{12} \mathrm{El}$ motor de todo el modelo es la inversión, e incremento de inversión quiere decir industrialización.

12. El modelo es tan formal que poco importa que el sector en cuestión sea agrícola $o$ industrial. No interesa quién y cómo se genera el incremento del capital o de los ingresos sino cuánto o en qué proporción lo hacen. 


\section{Las teorlas del desarrollo/modernización}

\subsection{Rasgos generales}

Ya hemos dicho al principio de este capítulo que el elemento central constitutivo de las teorias del desarrollo/modernización (TDM) es que reconocen la especificidad del subdesarrollo, y por otro lado su rechazo a la idea que el desarrollo se simplifica en el crecimiento de las variables macroeconómicas. ${ }^{13}$ Dentro de estas teorias podernos ubicar diversas corrientes que van desde las primeras TDM (Hirschman, Roseinstein, Mymal, Perroux, Lewis, Fei-Ranis, Senn, Dobb), pasando por los partidarios del "crecimiento hacia adentro" o las teorias de la dependencia (en su primera versión: Prebish y la Cepal, o su versión radicalizada: G. Frank, Marini, S. Amin), o los partidarios del "crecimiento hacia afuera" (Balassa, Friedman y los economistas de la "escuela de Chicago"), hasta llegar a las más recientes TDM denominadas "Pragmáticas" (Chenery, Moses, Steward, Streeten).

A las dos grandes caracteristicas de la TDM ya senaladas anadamos otras que deben ser tomadas en cuenta:

a. Su noción del desarrollo está aún impregnada de cierto dualismo que contempla el desarrollo como el paso/transformación del sector tradicional al sector moderno. Aunque hay que matizar que ese dualismo está menos presente en unas teorias que en otras como por ejemplo dentro de la teoria de la dependencia, sobre todo en su versión radical, donde los enfoques en términos de articulación de modos de producción dan una visión compleja y menos dualista del desarrollo.

Sin embargo, habria que decir también que, a diferencia de las teorias del crecimiento, su dualismo no es concebido de forma unilateral o inorgánico: en las TDM el sector atrasado no es un objeto pasivo que sufre o es sometido a las influencias y cambios del sector moderno, sea por la vía de la inyección de capital, de las relaciones mercantiles o del progreso técnico. Por tanto el ente activo del desarrollo no es sólo el sector moderno, sino también el atrasado. ${ }^{14}$ Es en tal sentido que el dualismo de la TDM es de carácter funcional: el polo tradicional es un sujeto activo, puesto en función de las necesidades del polo modemo. Las diversas relaciones que se establecen entre ambos sectores son objeto de estudio y definión dentro de los

14. En la teoría del crecimiento de Adelman el dualismo es sin embargo diferencial: el sector tradicional es un sujeto activo que bloquea el desarrollo a través de la variable demográfica. 
modelos de la TDM. No se trata de relaciones unilaterales donde sólo el sector moderno incide o transforma el tradicional sino que también éste determina la dinámica de aquél. Son relaciones orgánicas y no simple yuxtaposición de dos sectores. ${ }^{15}$ Su dualismo funcional puede ser expresado ya sea a nivel internacional (la periférica en función de las necesidades del centro) o ya sea a nivel interno (la agricultura en función de los requerimientos de la industrialización).

b. Poseen una visión crítica sobre el funcionamiento del capitalismo. Ya sea que se dé dentro del marco de la defensa del sistema y postule reformas para su mantenimiento, o se dé fuera de tal marco planteando una ruptura con el capitalismo. Son ópticas del desarrollo cuyas políticas sugieren la necesidad del cambio de estructuras, ya sea que se hagan en función de una mayor y mejor integración con el mercado mundial o en función del aprovechamiento interno del excedente económico. Son las demandas de estas transformaciones que llevan a las TDM a darle un rol activo e importante al Estado. Es éste quien debe impulsar y sentar las condiciones internas que permitan las nuevas orientaciones al proceso de acumulación. ${ }^{16} Y$ esta necesidad de la intervención del Estado como "agente modernizador" se encuentra aún presente, aunque pareciere paradójico, en las corrientes neo-liberales defensores del desarrollo hacia afuera. Creemos que incluso los partidarios de Friedman, Balassa y cia. no les queda más remedio que aceptar la presencia de un gobierno fuerte, capaz de transformar las estructuras económicas y políticas, antes orientadas hacia el mercado interno bajo el modelo de sustitución de importaciones, en unas estructuras extravertidas que respondan a la lógica de la nueva división internacional del trabajo.

¿Acaso uno de los países-ejemplo en la aplicación de las recetas neo-liberales como es el de Chile no ha requerido de una dictadura fuerte, que al principio no sólo abandonó toda gerencia y propiedad de muchas empresas públicas sino que su intervencionismo fue a tal grado de mantener largamente bajos niveles salariales (que poco tenian que ver con la dinámica del mercado y de la productividad marginal y más con las variables políticas de indole represiva) que

15. Aunque, como veremos más adelante, hay TDM cuyos análisis de las relaciones entre los dos sectores rayan con el dualismo unilateral e inorgánico.

16. En casi todas estas teorias (menos en el neo-liberalismo) hay una desconfianza en el sistema de precios, es decir, en la posibilidad de que el mercado por si mismo logre la reorientación del proceso de acumulación. 
posibilitarán la competitividad de los productos chilenos exportados. ${ }^{77}$

El planteamiento del cambio de estructuras y el rol activo asignado al Estado en ello da a las TDM un marcado sentido de la planificación y una significativa valorización a la elaboración de políticas o estrategias de desarrollo.

c. Las TDM acá expuestas abarcan sobre todo el periodo que va desde mediados de los anos 60 hasta principios de la década de los 80 . Sus origenes se remotan entonces a una época en que la expansión económica de post-guerra muestra un marcado descenso y en que los límites y problemas causados por el crecimiento acelerado hacen su aparición. Los fenómenos de pobreza, desigualdad social, de división creciente entre el Norte y el Sur se hacen más patentes. Al principio de este período cobran importancia las obras de Josué de Castro "Geografía del Hambre" (1949/51), en la que se detallan las condiciones de pobreza de los 2/3 de la humanidad, y la de R. Nurkse (1952) en las que se analizan las caracteristicas estructurales de la pobreza por medio de lo que el autor denomina "circulo vicioso de la pobreza" (no hay desarrollo porque no hay capitales, ni ingresos ni demanda, y no existen éstos porque no hay desarrollo). En el plano político-social es un momento histórico de fuertes luchas y conflictos, de reforzamiento de los movimientos de liberación (revolución Cubana, guerra de Vietnam, Argelia). El conflicto Este-Oeste pierde relativamente peso en favor del conflicto Norte-Sur. Es así, para el caso, que todo este tipo de caracteristicas históricas contribuirian al impulso de estrategias de desarrollo reformista, cuya concreción más visible en Latinoamérica fue la política fomentada por la Alianza para el Progreso durante el gobierno de Kennedy.

Son ese conjunto de factores los que "presionaban" a las teorias del desarrollo nacientes a considerar el subdesarrollo como sujeto específico de estudio, a introducir en sus modelos las variables no econó-

17. Se podrá argumentar que en el pensamiento neo-liberal la intervención estatal es concebida solamente para un periodo de transición de desmantelamiento de las estructuras anteriores, pero cabe preguntarse ¿Y la intervención del Estado chileno, "socializando las pérdidas" de las grandes empresas durante la crisis en 1982, es decir una vez ya en juego las nuevas estructuras extravertidas, es una intervención pasajera?. Por otro lado, aunque sólo se contemple para un monto de transición ¿no es ello ya un reconocimiento del rol correctivo y por ende positivo hasta cuando se entra en una economía "pura", de libre mercado que nunca ha existido? en este caso ¿Tiene sentido tanta descalificación de la intervención estatal en el seno del liberalismo? 
micas y colocar al sector no tradicional en una perspectiva más dinámica, así como a la proliferación de políticas concretas que favorecieran el cambio de estructuras.

\subsection{Caracteristicas de algunas teorias del desarrollo/modernización}

A pesar de los rasgos comunes sefialados, las TSM son diversas y diferenciadas. Intentaremos a continuación, no sin riesgo de caer en el simplismo, de hacer una clasificación de las mismas. ${ }^{18}$

En primer lugar establecemos una clasificación general de acuerdo al aspecto del desarrollo que es más remarcado en dichas teorías. Encontramos asi un primer grupo que pone el acento en el problema de la acumulación y de la eficacia del capital, a las que nos referimos como 1a. formulación de las TDM. Un segundo grupo acentúa el análisis en las "deformaciones" o problemas generados por la modemización-industrialización y la necesidad de sus correcciones, y que denominaremos 2a. Formulación de las TDM.

Dentro del primer grupo podemos realizar una subdivisión. 1) Por una parte están aquellas teorias que contemplan el logro del desarrollo en términos de la mejor distribución del capital o del proceso de acumulación (sea a nivel sectorial, regional, etc). La "mejor eficacia del capital" se obtiene y distribución balanceada o equilibrada (tesis de Roseiustein y Rodan), o a través de su inversión desbalanceada, con la creación de "polos de desarrollo" (Hirscman). 2) En otra parte pueden ubicarse las teorías que definen el desarrollo más adecuado de acuerdo a la manera de combinar los factores de producción (capital y trabajo) y en base al tipo de mercado y tipo general de bienes que habria que priorizar. La mejor eficacia del capital consiste en la utilización de técnicas intensivas en trabajo produciendo especialmente bienes de consumo para el mercado externo (modelo Fei-Ranis y el "ejemplo asiático"), o al contrario,

18. Nos parece arriesgada la clasificación que hacen Jacquemot y Raffinot sobre las teorias del desarrollo. Estos autores presentan dos grandes grupos de acuerdo a su posición frente al funcionamiento del capitalismo: aquellas teorlas que buscan el desarrollo por medio de la integración al capitalismo y las que lo hacen a través de la ruptura con el mismo. Esta clasificación tan gruesa nomina al primer grupo como corriente neo-clásica o liberal, por oposición a la segunda definida como radical, y coloca dentro del primero a teorlas que no nos parecen ser de corte liberal. Nos referimos a las teorías de Hirschman o Harrod-Domar, que más bien responden a escuelas neokeynesianas y/o estructuralistas.

JACQUEMOT, Pierre y RAFFINOT, Marc. Accumulation et Développement. Editions L'Harmattan. Paris. Págs 16 a 30. 
en la utilización de técnicas intensivas en capital produciendo bienes de equipo para el mercado interno (modelo M. Dobb y Kumar Senn y el ejemplo Indio y Soviético).

En el segundo grupo, referente a la 2a. Formulación de las TDM, podemos hacer también una subdivisión a partir de su concepción sobre las causas que provocan las deformaciones de la modernización, es decir, del subdesarrollo, y de las soluciones propuestas para corregir o eliminar tales deformaciones. Dependencia y necesidad de desarrollo hacia adentro (1 a. y 2a. versión de la Teoria de la Dependencia), trabas al libre juego de las fuerzas del mercado y necesidad del desarrollo hacia afuera (Teoria del Desarrollo Extrovertido); "deformaciones parciales" que aparecen en el proceso de modernización y que pueden y deben ser corregidas por medio de la mejor distribución de los ingresos, o por una adecuada canalización del sector informal, o ya sea también por la utilización de tecnologia apropiada, o de la satisfacción de las necesidades básicas de la población (TDM Pragmáticas).

\subsubsection{Las primeras formulaclones de las Teorlas del Desarrollo/Mo- dernización}

Como ya lo indicamos en anteriores ocasiones, este tipo de teorias, en tanto que teorias de la modernización, conciben el desarrollo como despliegue acelerado del proceso de industrialización. Su especificidad reside en la forma de alcanzar ese proceso. Tomando como base sus caracteristicas generales, antes anotadas, podemos pasar a exponer los rasgos de esas teorias con más detalle:

a) Según las primeras formulaciones de las TDM el simple crecimiento equilibrado de la economia no es suficiente para lograr el desarrollo. Puede haber crecimiento sin acumulación, puede existir crecimiento junto a la ineficacia del capital; y a la larga, la falta de acumulación y eficacia del capital conducirá a frenar y limitar el mismo crecimiento.

b) Hace falta considerar el proceso de acumulación en todas sus dimensiones y no sólo en su aumento cuantitativo. Estas dimensiones incluyen variables no estrictamente económicas: la localización sectorial o espacial del capital, el tipo general de técnica, de mercado y de productos asi como el marco socio-político que orienta adecuadamente esos "nuevos" aspectos del proceso de acumulación del capital.

c) El "nuevo" proceso de acumulación implica la modernización del sector atrasado o de la agricultura en función de la dinámica del sector moderno 0 industrial. La modernización de la agricultura se realiza 
entonces tomando esencialmente en cuenta su rol en el abastecimiento de mano de obra, alimentos y materias primas al sector industrial.

d) Se requiere, para reorientar la acumulación y para modemizar la agricultura, el cambio de estructuras; dentro del cual la Reforma Agraria juega un papel preponderante asi como el del Estado y de las clases medias emergentes.

En el primer grupo de estas teorias el debate del desarrollo gira en torno a la distribución balanceada o desbalanceada de las inversiones 0 del capital.

Para Roseistein-Rodan (cuyas tesis datan de los 1943) la acumulaciónindustrialización debe llevarse a cabo en forma balanceada, a pesar de la necesidad de un "big push" o impulso inicial. No sólo hay que lograr un crecimiento equilibrado sino, y sobre todo, un proceso de acumulación equilibrado que reparta equitativamente las inversiones entre los diferentes sectores, dentro de los cuales el agropecuario tiene prioridad. De igual manera habria que evitar la concentración espacial de la Industrialización, de forma de repartir los proyectos de modernización a todas las regiones. La distribución balanceada del capital podría llevarse a cabo si no bloquearan las interdependencias de la oferta y la demanda, es decir a través de la liberalización del mercado. Por otra parte, R. Nurkse también propone una distribución balanceada de la inversión o del capital como camino para romper con el círculo de la pobreza. Para oste autor, según C. Furtado, "la nptura del "impase" serla posible sólo mediante la implantación simultánea de un conjunto de proyectos, complementarios entre sí... En este caso, industrialización no es 10 mismo que crecimiento exclusivo del sector industrial, sino que corresponde a una expansión equilibrada de todos los sectores para satisfacer una demanda global que se diversifica con los incrementos de los ingresos". 10

En contra de la postura anterior, uno de los considerados pioneros de las TDM, A.O. Hirschman (1964), sostiene la tesis de la conveñiencia de la distribución desbalanceada del capital. Esta tiene su base en la concepción del "crecimiento transmitido": el desarrollo de un pais o de una región vendría dado por la concentración de un moderno proceso de acumulación en unos cuantos "polos industriales" que irradiarian sus efectos benéficos de arrastre al resto de la economia. Ahora bien, hay que decir que la idea de una distribución desequilibrada no se plantea

19. FURTADO, Celso. Teorla y Politica del Desarrollo Económico. Editorial Siglo XXI. 13a. Edición. México 1987. Pág. 245. 
tanto porque sea mejor que la equilibrada, sino porque, según Hirschman, las posibilidades de conseguir ésta (que demada un sólido sistema de planificación y coordinación) son casi nulas dentro de los paises subdesarrolldos.

Hay que remarcar que no hay una oposición frontal entre las dos posturas anteriores. Como lo afirma el mismo Furtado "es posible presentar al conjunto de proyectos complementarios que desempenarán el papel de "big push", según la expresión de Roseintein-Rodan, como un "polo" desde el cual deberá propagarse, en la fase subsiguiente al rompimiento de la inercia, el impulso del crecimiento... En este caso, la política de desarrollo equilibrado asumirá la forma de creación de polos de crecimiento". ${ }^{20}$

El segundo grupo de teorías concentra la discusión sobre la problemática del desarrollo alrededor de una serie de "tipos generales": tipo de técnica a utilizar, tipo de mercado para producir y tipo de bienes producidos. A pesar de ser estos aspectos claves a tener en cuenta en una nueva concepción del desarrollo, la definición de los "tipos" es tan general o gruesa que no llega a penetrar en la problemática de los contenidos concretos que asume el proceso de acumulación. Son generalidades que abarcan UN tipo de técnica (las posibles combinaciones eficaces entre el capital y el trabajo), UN tipo de orientación del mercado (si es externo o interno), y UN tipo de definición de los bienes (si son de consumo, intermedios o de capital), los cuales no son suficientes para calificar el contenido específico de un proceso de acumulación. Este, sin embargo, comprende varias posibilidades técnicas y no sólo una (referente a sus relaciones cuantitativas) así como contempla varias dimensiones del mercado y multiples rasgos del valor de uso de los bienes.

Partiendo del "modelo madre" elaborado por A. Lewis a principios de los años 50, ${ }^{21}$ el modelo presentado por Fei (1964) sostiene que la mejor manera de maximizar la eficacia del capital y del proceso de acumulación es un desarrollo que promueve unas técnicas "labour using" o intensivas en trabajo, orientadas a producir prioritariamente bienes industriales de consumo ligero, que aprovechando las ventajas comparativas se destinen preferencialmente al mercado mundial. Son por otra parte teorias inspiradas en la experiencia japonesa de fines del siglo pasado y comienzos del presente, asi como en los procesos de "despegue" de los llamados Nuevos Países Industrializados (NIP) del Sud-Este de Asia.

20. FURTADO, Celso. Ibid. Pág. 247.

21. Es un modelo que vale la pena ser estudiado para el análisis de las relaciones entre la agricultura y la industria. 
En una óptica diferente, e inspirada más bien en la experiencia de Industrialización acelerada de la Unión Soviética de los anos 30-40, los planteamientos de Maurice Dobb y del Indio Kumar-Senn (1965) van encaminados al uso de unas técnicas "labour saving" o intensivas en capital, que tiendan a producir bienes de equipo destinados principalmente a satisfacer las demandas de la modernización interna (que comprende una primera fase de equipamiento moderno de la agricultura). Hay que hacer notar que la experiencia de desarrollo y planificación en la India de los anos 60 estuvo muy influenciada por este tipo de ideas.

\subsubsection{La segunda formulaclón de las Teorias del Desarrollo/Moder- nlzación}

Los estudios enmarcados dentro de la segunda formulación de las TDM datan desde principio de los anos 50 , sobre todo a partir de los trabajos de R. Prebisch, G. Myrnal y F. Perroux. Pero adquieren un rango predominante desde mediados de los anos 60 . Todos ellos, inclu80 los pertenecientes a corrientes marxistas, conciben el desarrollo como proceso acelerado de industrialización. Sus diferencias residen en los análisis sobre las causas que impiden tal industrialización y en los diferentes caminos propuestos para adentrarse en tal dinámica.

En consecuencia distinguiremos tres grandes grupos de teorias de acuerdo a sus nociones respecto a las causas y naturaleza del fenómeno del "subdesarrollo", asi como de las recetas recomendadas para salir de tal estado. Se podria identificar como: a) La Teoria de la Dependencla. b) La Teoria del "Desarrollo Extrovertido y c) La Teoría del "Desarrollo Pragmático".

En términos globales las tres teorias tienen en común la idea que el desarrollo no es simple crecimiento... aunque las tesis del desarrollo extrovertido se encuentren en este punto cercanas a las teorias del crecimiento. Asimismo no se limitan al análisis de las variables económicas... aunque hay posturas que priorizan demasiado las relaciones económicas y relegan las políticas, como las que encontramos con frecuencia dentro de la teoría del desarrollo extrovertido o en la que llamaremos 1a. versión de la teoría de la dependencia. Son por otro lado teorias que entienden el desarrollo de manera funcional... aunque para algunas tal funcionalidad solamente signifique la desaparición o transformación del sector atrasado en moderno (como en las tesis del desarrollo extrovertido); o para otras signifique su mantenimiento o potenciación (como en algunas posturas al interor de la que denominaremos 2a. versión de la leoria de la dependencia que tratan sobre la articulación de los modos de producción, o dentro de la teoría del desarrollo pragmático que tratan 
sobre el "rescate" del sector informal). Finalmente, sus planteamientos críticos los llevan a postular el cambio de estructuras... aunque para unos se realicen en favor de la continuidad o reforzamiento del sistema capitalista (Teoria del Desarrollo Extrovertido, Teoria del Desarrollo Pragmática y 1a. versión de la Teoria de la Dependencia) y para otros en vista a la ruptura con el mismo (2a. versión de la Teoria de la Dependencia). Detengamonos en algunas particularidades de estas tres teorias.

\section{La Teoria de la Dependencla}

Uno de los origenes relevantes de la Teoria de la Dependencia podemos divisarlo durante los años cincuenta en los trabajos de Raúl Prebisch (1950) y los primeros economistas de la Comisión Económica de las Naciones Unidas para América Latina (CEPAL), Francois Perroux (1955) y Gurnar Mymal (1959). Para éstos la principal causa del subdesarrollo residía en la dependencia a que están sometidos los paises denominados periféricos respecto a los paises del centro, ${ }^{22}$ y por ende la superación del subdesarrollo se basa en el "desarrollo hacia adentro". Es decir que se trata de "una política de recuperación del excedente nacional y de su utilización en las actividades productivas, permitiendo "interiorizar" la acumulacion del capital". ${ }^{23}$ De esta noción surge con fuerza la estratégia de sustitución de importaciones. En otro orden, es preciso sefalar que fueron ciertas características negativas de la expansión económica de post guerra, las que favorecieron la elaboración y difusión de la teoria de la dependencia: creciente desnivel tecnológico entre los paises del centro y los de la periferia, tendencia al deterioro en el precio de las materias primas, "precios monopólicos" en los bienes manufacturados dentro del mercado internacional y rol mayor de las empresas transnacionales en el control e imposición de los mismos, etc.

Dentro de la teoria de la dependencia existen diferencias teóricas, y cronológicas, que nos llevarán a distinguir una primera y una segunda versión de la misma.

- La primera versión de la Teoria de la Dependencia está más en línea y continuidad con los trabajos de Prebisch e incluye a la mayoría de los economistas surgidos de la CEPAL Esta corriente ha tenido varios calificativos según los criterios empleados en su estudio: Humanișta (Jac-

22. Para ciertos autores (Rosier, Raffinot, Jacquemot) los términos centroperiféria" fueron rehabilitados por Prebisch, $H$. Singer y la CEPAL a partir de la teorla del imperialismo de Lenin y bujarín (acorde a Jacquemot y Raffinot) o de Rosa Luxemburgo (según Rosier).

23. JACQUEMOT y RAFFINOT. Op. Cit. Pág. 32. 
quemot y Raffinot), Estructuralista (Machado), Desarrollista (RosierDockés), etc.

Sus investigaciones sobre las causas y mecanismos del subdesartollo se concentran a nivel internacional. Abordan de manera especial el problema de la transferencia de excedentes de los países periféricos hacia los palses centrales, sobre todo por medio del mecanismo del deterioro de los términos de intercambio. Y el camino para superar tal problemática es a través de la profundización de una estrategia de Sustitución de Importaciones que comenzando por los bienes de consumo no duradero lleve a la sustitución de importaciones de los bienes de Capital. ${ }^{24}$

Años más tarde otros autores pertenecientes a la misma escuela de la CEPAL irán mostrando los límites de esa estratégia de sustitución de importaciones (SM). Asi en la década de los 60, Furtado2s analizará los problemas estructurales que confronta la estrategia de SM. Este gran exponente brasileno de la teoria de la dependencia prioriza el estudio de los factores económicos que frenan o distorsionan el proceso de industrialización por la via de la SM. De tal forma que diversas condiciones estructurales tanto del lado de la oferta como de la demanda se combinan para producir una tendencia al estancamiento $y$ al desequilibrio externo de las economias periféricas. ${ }^{26}$

Esas críticas a la SM surgidas desde el interior de la 1a. versión de la Teoria de la Dependencia (TD) se pueden complementar con otras que provienen de fuera de la misma. En primer lugar los análisis de la 1a. versión, a pesar de no reducirse sólo a los aspectos cuantitativos del desarrollo, rayan con el economismo, a tal grado que algunas entre ellas llegan a identificar el fenómeno de la dependencia con los simples problemas deficitarios de la Balanza de Pagos. Pero resulta que las crecientes dificultades de la industrialización por medio de la SM no se debian únicamente a las particularidades estructurales de las economias periféricas sino también al contenido de las relaciones políticas, intemas

24. No cabe duda que estas ideas tuvieron un fuerte impacto durante los años 50 en la implementación de las estratégias industriales de la mayorla de paises Latinoamericanos.

25. FURTADO, Celso. Op. cit. pág. 250 a 277.

26. Por el lado de la oferta, el crecimiento económico conlleva una elevación del coeficiente de capital por trabajador que, dentro de unas estructuras heterogéneas y compartimentadas y en un contexto de excedente estructural de fuerza de trabajo, favorecen el desarrollo de industrias cuyas "funciones de producción presentan coeficientes menos flexibles" (Furtado), como serla el caso de las industrias de bienes de consumo duradero, en las que 
e internacionales, en las que se desenvolvian tales economias. El problema del deterioro de los términos de intercambio, de la dependencia tecnológica, de la concentración de los ingresos, de la elevación del coeficiente de las importaciones, etc. no eran exclusivamente problemas causados por deformaciones $o$ insuficiencias de las fuerzas del mercado (los cuales podian ser entrentados y mejor encausados por un proceso creciente de la planificación), sino también dificultades originadas en las deformaciones e insuficiencias en las relaciones de fuerza del poder político a escala nacional y mundial... que no sólo requerian de una buena planificación sino también de una ruptura política con el sistema dominante. Al contrario, las primeras versiones de la TD promovieron el fortalecimiento de una burguesia nacional industrial.

En segundo lugar la visión dualista de la 1a. versión conducía a privilegiar, de manera casi exclusiva, los análisis sobre la dinámica del sector moderno, donde el sector tradicional era percibido solamente en su funcionalidad respecto a aquél (como simple abastecedor de mano de obra, alimentos y materias primas). Su funcionalidad era tal que marginaba los análisis sobre el contenido y características del sector tradicional y se detenía únicamente en el estudio de "las funciones" del mismo. Esta falta de investigaciones del sector no capitalista como sujeto de las mismas y los superticiales conocimientos sobre su racionalidad fueron "vacios" que, por ejemplo, no contribuyeron a entender "otros obstáculos estructurales" que se presentaron a la puesta en marcha y funcionamiento de la Reforma Agraria; asi como el desestimar los "obstáculos políticos" impidieron comprender bien la permanencia y agudización de la concentración de los ingresos a pesar de las correcciones o reformas económicas al proceso de SM.

Las progresivas limitantes al proceso de SM posteriores a la década de los 50, las serias dificultades inflacionarias, el aumento constante de

el grado de seleción técnica es limitado. Rigidez que a la larga contribuye al estanciamiento de las inversiones. Por el lado de la demanda, la existencia permanente de un mercado heterogéneo y reducido desfavorecen los positivos efectos multiplicadores del empleo y del ingreso. A medida que el proceso de SM avanza los efectos multiplicadores del ingreso tienden a estabilizarse (porque el crecimiento de las industrias sustitutivas tienen un límite y los ingresos adicionales tenderán entonces a destinarse a las importaciones) y los del empleo a reducirse (las nuevas industrias sustitutivas son cada vez más modernas o intensivas en capital). En cuanto a los desequilibrios externos Furtado destaca la propensión al aumento del coeficiente de importaciones que acompaña sobre todo las últimas fases de la SM. 
las desigualdades socio-económicas, la agudización del fenómeno de la dependencia, la mayor separación entre el Norte y el Sur, el empuje a los movimientos político-sociales dado por la Revolución Cubana, entre otros factores, llevaron a muchas investigaciones a una profundización de la temática de la dependencia. Es así que la búsqueda de alternativas explicativas a ésta, acompanada de una radicalización de los planteamientos de la 1a. versión, condujo a la elaboración en la década de los 60 de lo que hemos denominado 2a. versión de la TD.

La segunda versión de la Teoría de la Dependencia durante los anos 60 se desarrolló en buena medida bajo la aplicación del marxismo al fenómeno de la dependencia; más específicamente por medio del Materialismo Histórico y la Teoria del Imperialismo. En esta perspectiva los frenos al proceso de industrialización no sólo se encuentran en las relaciones de dominio y dependencia a nivel internacional sino además en la "no correspondencia" de unas relaciones de producción con un determinado grado de desarrollo de las fuerzas productivas.

Hay opiniones que estiman que la $2 a$. versión priorizaba también las variables externas al subdesarrollo. Pero aunque no hay duda que el fenómeno de la dependencia era medular en el cuerpo teórico de esta 2a. versión (como lo ilustran los mismos títulos de sus obras: "El intercambio desigual" de Enmanuel, "La Dialéctica de la Dependencia" de Marini, "La acumulacion a escala mundial" de Amin), sin embargo, hay una mayor riqueza y profundización en los obstáculos internos al desarrollo.27 Estos contenidos permiten justamente especificar y ampliar algunas caracteristicas de la $2 a$. versión de la TD:

a. La problemática del desarrollo no sólo debe incluir variables económicas sino además las socio-políticas ya que el desarrollo es, ante todo, un problema de lucha de clases. Sin embargo, en ciertas opi-

27. Jacquemot y Raffinot exponen dos maneras de enfocar la temática de la dependencia. Por un lado está aquella que establece la dialéctica centro periferia en términos de la "dominación por el sistema de precios", es decir la que da preferencia a los análisis a nivel de la esfera de la circulación, especialmente a escala mundial. Una figura relevante bajo la perspectiva marxista seria A. Enmanuel y su obra "El Intercambio Desigual". Por otro lado está la que aborda la relación dominación/dependencia desde el punto de vista del proceso de internacionalización del capital y que prioriza los cambios en la esfera de la producción interna debidos a las nuevas formas de división y organización del trabajo a escala mundial. Se destacaria acá a C. Palloix y su trabajo "Las firmas multinacionales y el proceso de internacionalización". Este último fijaria más la atención en las estructuras internas que el primero. 
niones (Jacquemot y Raffinot) la 2a. versión realiza el análisis de la lucha de clases más que todo en términos formales: como lo ejemplificaria la tesis de R.R. Marini sobre la "sobrexplotación" de la fuerza de trabajo, en la que se hace omisión a las luchas políticas y sindicales reales en la determinación de las formas concretas de utilización de los trabajadores y de la tasa de salarios.

b. La inclusión de las variables socio-culturales favoreció la aparición de una "dimensión antropológica" en el panorama del desarrollo; lo que a su vez proporcionaba al dualismo funcional que aún poseian estas teorias un carácter más de proceso que de funciones fijas: ya no se trataria tanto de establecer la coexistencia funcional entre un sector moderno con uno atrasado sino de identificar un proceso de articulación y penetración del modo de producción capitalista sobre los modos de producción no capitalistas. ${ }^{28}$ Los trabajos del campo de P. Ph. Rey (1973) y de C. Meillassoux ayudarian a divisar el desarrollo no como un pasaje del polo atrasado al modemo o la conversión de estructuras pre-capitalistas en capitalistas sino en términos de un proceso de articulación que el modo de producción dominante establece dialécticamente con el modo de producción dependiente o no capitalista, al que somete, ya sea penetrándolo para destruirlo o para conservarlo. Valga indicar que serian diversos elementos, sobre todo socio-culturales, los que permiten a las comunidades 0 actividades precapitalistas la resistencia a la penetración de las relaciones capitalistas. Pero que serian asimismo ciertos factores político-económicos los que ayudan al modo de producción capitalista a sacar provecho y ventaja de tal resistencia. Este aprovechamiento contribuye a explicar el mantenimiento hoy dia de formas de producción artesanales al lado de la gran industria o del minifundio al lado de las modernas explotaciones agricolas 0 agroindustriales.

c. Su visión crítica del desarrollo del capitalismo se sitúa en buena parte alrededor de la contradición existente entre el desarrollo de las fuerzas productivas y las relaciones de producción: a un cierto momento éstas "traban" la expansión de aquéllas, es decir, que son las relaciones de producción capitalista las que frenan el desarrollo de

28. Aunque no estamos muy de acuerdo con Jacquemot y Raffinot en la ópinión de que la 2a. versión de la TD haya superado completamente el dualismo funcional, ya que a pesar que la tesis sobre articulación de modos de producción pues significa un abandono del mismo, nos parece que lo $s i$ guen manteniendo en su apreciación sobre las relaciones entre el agro y la industria, en la medida que el primero sigue puesto en función de las necesidades de la industrialización en el logro del desarrollo. 
las fuerzas productivas o sea la industrialización. Todo desarrollo exige entonces una ruptura con el sistema capitalista. Al tiempo que el nivel alcanzado por la "liberalización" de las fuerzas productivas presiona por el cambio de las relaciones de producción capitalistas y hace inevitable el advenimiento del socialismo."

Las nociones que del desarrollo posee la $2 \mathrm{a}$. versión de la TD significan un avance respecto a las teorias precedentes, y la importancia de sus aportes teóricos y prácticos nos parece de gran envergadura. Sin embargo, habría que traer a cuenta algunos comentarios críticos a la misma:

- Las teorias de la 2a. versión siguen manteniendo la idea que desarrollo es igual a industrialización, la cual es concebida en términos de "desarrollo de las fuerzas productivas". Éstas a su vez son definidas "en términos técnicos de secuencia de industrialización" (Rosier)..$^{30}$

Estos planteamientos son más evidentes en el caso de aquellas concepciones o estratégias que tienen su inspiración en el proceso de industrialización acelerada y planificación centralizada en la URSS, especialmente en la época staliniana. Una industrialización basada en un severo sometimiento de la agricultura con el fin de extraerle los excedentes necesario al rápido establecimiento de una industria pesada. ${ }^{31}$

- Su visión del desarrollo, o más exactamente del desarrollo de las fuerzas productivas, adolece de un determinismo tecnológico que presenta la técnica en si como el principal motor del desarrollo... a tal punto que caen en "la contradicción de querer construir el socialismo con técnicas producidas por el capital". ${ }^{32}$ Por tanto, las relaciones de producción y las fuerzas productivas son vistos como dos cosas dife-

29. La conquista del socialismo es entonces expuesta como una ley histórica inevitable, gobernada por las relaciones contradictorias entre las fuerzas productivas y las relaciones de producción, y no como una posibilidad histórica gobernada por los múltiples y complejas forma que adquiere la lucha de clases.

30. Ello a pesar que, según el mismo Rosier, éste tipo de teorias comenzarian a adentrarse en la especificación del "contenido" del desarrollo, en la medida que "éste no es concebido como un si mismo, sino que se encuentra situado históricamente y socialmente en el cuadro de un Modo de Producción dado, es decir analizado en estrecha relación con las relaciones sociales de producción determinadas". ROSIER, Bernard. Op. Cit. Pág. 107.

31. Hay acá convergencia con las tesis de Dobb y Senn.

32. ROSIER y DOCKES. L'Histoire Ambigüe (Croissance et Développment en question 
rentes, donde estas últimas determinan a las primeras: la técnica del molino de agua determinó la creación del sefior feudal y la de la máquina de vapor llevó a la formación de los capitalistas. Pero como lo indicamos en otra ocasión, las fuerzas productivas no son independientes de las relaciones de producción. Lejos de ello, son expresión de éstas. $Y$ en tal sentido, como diria Rosier citando al economista norteamericano Marglin "No es la máquina de vapor que ha hecho el capitalismo (Marx) sino es este quien la ha producido como innovación mayor y masiva". ${ }^{33}$

Esa concepción determinista del desarrollo técnico de las fuerzas productivas sobre las relaciones de producción conduce a la corriente marxista predominante a hablar de "nivel de desarrollo de las fuerzas productivas" reduciéndolo a su mero rango cuantitativo, en lugar de hablar, como lo propone Rosier, de "tipo de desarrollo de las fuerzas productivas", en el que se prioriza el contenido o los aspectos cualitativos que asumen esas fuerzas de la producción.

- El evolucionismo en que cae la 2a. versión de la TD (ver para el caso el paso obligado del desarrollo de sociedades que se expone en el ya clásico libro de Marta Harnecker, "Conceptos elementales del materialismo histórico", es decir la secuencia de sociedad primitiva o comunitaria-modo de producción esclavista-feudalismo-capitalismosocialismo) y su determinismo histórico (ley social sobre la inevitabilidad del socialismo), son factores que han impregnado a dicha teoria de un pesado "manto ideológico" que nublaba y dificultaba la elaboración de estratégias concretas de cambio de las sociedades. Es en parte debido a ello que dentro de esta versión de la TD abundaron los análisis críticos sobre el funcionamiento del sistema capitalista 0 a las teorias que lo defendian, pero eran escasas las propuestas precisas de su transformación y la elaboración de instrumentos específicos para llevarlo a cabo. Si la llegada del socialismo era inevitable. ¿Para qué dedicarle tiempo a la formulación de estratégias concretas que lo hicieran posible?

Hechos los anteriores comentarios críticos y visto en su conjunto la TD, pasemos al estudio de otro grupo de teorias del desarrollo, es decir a las pertenecientes al modelo de desarrollo extrovertido.

\section{La teoría del desarrollo extrovertido}

Para esta corriente de pensamiento la mejor forma de alcanzar el desarrollo/modernización es por medio del comercio, o más concreta-

33. ROSER. Op. Cit. Pág. 115. 
mente a través de la integración de los paises subdesarrollados al mercado mundial, gracias al proceso de especialización del sistema productivo. Su postulado principal es el del "desarrollo hacia afuera" por oposición al del "desarrollo hacia adentro". ${ }^{34}$

Ciertamente sus origenes se remontan al siglo pasado con la Teoria de las Ventajas Compartivas de D. Ricardo, y más recientemente, ya en el presente siglo con el denominado modelo de H.O.S. (Hecksher-OhlinSamuelson). Son por otra parte teorias que han servido de base a la tradicional división internacional del trabajo que relega a los paises del Tercer Mundo el rol de especializarse en la exportación de productos primarios.

Si a pesar de su antiguedad e importancia histórica no hemos hecho antes referencia a la Teoria del Desarrollo Extrovertido (TD) ha sido, en parte, porque interesa conocer su versión actual. Es decir, aquellas TDE que en la década de los 70 y 80 han dado pie a hablar de la "contrarevolución liberal". Expresión de ésta son las tesis de B. Balassa., Little, M. Friedman y la escuela de Chicago, las recetas del FMl y de otros muchos organismos financieros internacionales o multinacionales inspirados en lo que se dió en llamar la "Reaganomics".

Un conjunto de acontecimientos históricos favorecieron el fuerte reaparecimiento de las TDE. En primer lugar, renace como reacción a las tesis de la TD y del "desarrollo hacia adentro" basados en la estratégia de SM.. El agotamiento y límites que presentaba ese tipo de desarrollo a finales de la década del 60 y principios de los 70 servia de "catapulta" al lanzamiento de las ideas del desarrollo hacia afuera. En segundo lugar, la reaparición del desarrollo extrovertivo se lleva a cabo en el marco de una reestructuración de la economía mundial y de una nueva división internacional del trabajo que otorgaba un papel preponderante a la dinámica del comercio mundial y un nuevo rol a los paises periféricos (participación de éstos con nuevos bienes en un mercado exterior transnacionalizado). En tercer lugar, luego de la profundización de la crisis del modelo de SM y del "shock petrolero" de los anos 73/75, la contra-revolución liberal encuentra un reforzamiento en la extracción selectiva de algunas consecuencias de dicho impacto económico. Es

34. Lo que refleja un viejo debate entre la postura de Ricardo que justificaba la expansión del libre comercio de la otrora potencia comercial inglesa, y la posición crítica expresada por el economista alemán List que defendia los intereses de la Europa Continental, menos desarrollada que Inglaterra y de relativa poca presencia en el mercado mundial, y que recomendaba más bien una política proteccionista y de "desarrollo hacia adentro" 
aqul que Balassa ${ }^{35}$ llega a sostener que los paises que mejor se adaptaron a las consecuencias del shock fueron aquellos que orientaron sus economias a la exportación, redujeron el proteccionismo y liberaron las tasas de cambio y tipos de interés y que redujeron al gasto público (Indonesia, Singapur, Taiwan, Corea del Sur, Chile, Uruguay, Kenia, Mauritania). Mientras que los paises que optaron por el "encerramiento", el proteccionismo y el control de los tipos de cambio e interés, el incremento del gasto público e incurrieron en un mayor endeudamiento, fueron los que más sufrieron los efectos de la crisis del petróleo y del periodo depresivo que lo acompanó (casos de Argentina, México, Brasil, (srael).

Las fundamentales nociones que la TDE tiene sobre el desarrollo estarian marcadas por las siguientes características:

a. Desarrollarse significa una modernización-industrialización por medio de la integración de las estructuras productivas nacionales al mercado mundial. El motor del desarrollo es el comercio. Las estructuras nacionales deben entonces especializarse en aquellos sectores o actividades que posean mayores ventajas comparativas, las cuales están dadas por las mayores dotaciones y precios bajos de los recursos productivos; para los paises subdesarrollados ello se refiere normalmente a la abundancia y baratura de la fuerza de trabajo. En la nueva división intemacional de trabajo (DIT) tendrian cabida no sólo los productos tradicionales sino, y sobre todo, nuevos productos primarios o industriales producidos a intensidad del factor trabajo. En los obstáculos al libre comercio se encontrarian entonces las principales causas del atraso, y las soluciones al mismo pasan por las estratégias y políticas con base en el "laisser-faire".

b) A ese nivel, la TED parece aproximarse a las Teorias del Crecimiento en cuanto limitan sus análisis del subdesarrollo a variables estrictamente económicas. No obstante nos parece que la TDE, paradójicamente a los mismos principios del "laisser-faire", introduce implicitamente otras variables no económicas, dentro de la que destacamos el rol del Estado, en el sentido que ya hemos anotado.

c. Asimismo se aleja de las Teorias del Crecimiento en cuanto a que sus modelos no son tanto construcciones formales y númericas sino que incorporan proposiciones muy concretas. Ahi está para muestra el gran despliegue y aplicación por todas partes del mundo de las recetas neoliberales.

35. BALASSA, Bela. Structural Adjusment Polices in developing Economics. World Development. Gran Bretaña. Enero 82. Pág. 23 a 38. 
d. Aparentemente es cercano al dualismo de las Teorias del Crecimiento. Sin embargo, más bien participan de un dualismo funcional y más complejo donde el sector atrasado no posee un carácter pasivo y no está destinado a transformarse en un sector moderno y condenado por ello a desaparecer, sino donde el polo atrasado puede ser conservado en aras de formas diferentes de integración al mercado mundial. De acá la importancia que en el modelo tienen las denominantes "economias de sub-contratación" que establecen los complejos agroindustriales orientados a la exportación con las explotaciones campesinas (como en México o en Chile), o la vasta red de pequena producción artesanal sometida a contratos diversos con las grandes industrias de exportación del sud-este asiático.

\section{Las teorías del desarrollo pragmático *}

A este conjunto de teorias, que surgen con vigor en la década de los 80 , se les conoce como pragmáticas en la medida que ponen el acento en la resolución de los problemas específicos o distorsiones que acompanan el proceso de modernización. Hay pues una percepción más realista del fenómeno del subdesarrollo. Percepción que ha sido sensibilizada por las mismas condiciones históricas actuales del Tercer Mundo: a pesar de experimentar altas tasas de crecimiento, especialmente en la década de los 50 y 60, la mayoria de los paises subdesarrollados han conocido a la par un incremento de desempleo, de las desigualdades sociales y económicas, de la dependencia externa (agravada hoy en dia por la enorme deuda y la creciente dependencia tecnológica), de la pobreza, etc.

Los principales sustentadores $u$ operadores de estas teorias son los organismos internacionales: Banco Mundial, OIT, FAO, organismos de la ONU. Su acción se ve forzada por el hecho de darse en un periodo histórico de relativo crecimiento de los paises del Norte que posibilita una mayor canalización de fondos hacia proyectos destinados a paliar problemáticas concretas del subdesarrollo.

\section{Otros rasgos de la teorla del desarrollo pragmático (TDP) son las siguientes:}

a. La primordial causa del subdesarrollo reside en las deformaciones que aparecen durante el proceso de modernización: mala distribución de los ingresos, desempleo, marginación socio-económica de las mayorias, tecnologias inapropiadas, etc. La solución al problema del desarrollo se encuentra entonces en la corrección de tales deformaciones. La modemización en si no es puesta en cuestion, no es incluída como causa misma del problema. 
b. Disponen de una visión más integral del fenómeno del subdesarrollo en la medida que su solución o superación no abarca solamente los aspectos económicos sino que penetra también en el terreno de los "correctivos" de indole política/social.

c. Dicho fenómeno es también percibido en forma más compleja. Por un lado hay cierto abandono del dualismo como lo ilustran algunas TDP que introducen como sujeto de estudio un "tercer sector", es decir el llamado sector informal (no se consideran sólo dos sectores, el agrario y el industrial) o un "segundo" grupo de paises del Tercer Mundo como son los denominados Nuevos Países Industrializados o los países de la OPEP (no se contempla sólo una relación dual entre centro y una periferia homogenizada). Por otro lado hay cienta ampliación del "abanico de posibilidades" al desarrollo: éste no sólo está formado por la posibilidad de utilización de tecnología moderna creada en el Norte sino también por una tecnologia apropiada generada en los propios paises del Sur.

d. A pesar de su mayor realismo, integridad y complejidad analitica las TDP padecen de una visión crítica limitada. Ya hemos anotado que estas teorias, en su generalidad, no tratan de cuestionar el sistema capitalista como tal y su sendero modemizante sino simplemente el corregir las deformaciones que se producen en su dinámica y recorrido. Se "descubre" al sector informal pero con objeto de hacerlo funcional al proceso de acumulación del capital. Como lo ilustra un antículo de uno de los exponentes de este tipo de teorias, se trata de repartir ingresos pero para producir tasas elevadas de crecimiento y un proceso acelerado de industrialización ${ }^{36}$ Se conciben políticas tendientes a priorizar la satisfacción de las necesidades básicas de la población pero, más que para mejorar la calidad de sus formas de vida, lo que se pretende es nutrir mejor a los trabajadores para que puedan producir más en función de las necesidades de acumulación del capital. Finalmente, se busca el uso de tecnologías apropiadas pero la noción de "apropiado" se reduce sólo a tecnologias (normalmente concebidas como modernas) que se adapten al ecosistema para elevar las tasas de productividad, y dice muy poco sobre la adaptación de técnicas (modernas o no) acordes a un proyecto independiente, basado en la cultura e intereses de los grupos populares. ${ }^{37}$

36. CHENERY y AHLUWALIA. A Model of distribution and Growth. En Redistribution with Growth. Oxford University Press. 1974. Pág. 209-235.

37. Es en tal sentido que Rosier afirmaria que "por tecnologia apropiada nosotros no entendemos solamente tecnologia frente a las exigencias tecnológicas, sino igualmente coherente con relación a un proyecto social al cual la 
Habría que anadir respecto al último punto que el uso de tecnología apropiada vista desde una óptica productiva, no es garantía de disminución de los grados de dependencia que definen el subdesarrollo. Sobre el tema, y a propósito del uso de la biotecnología (de las que pueden desprenderse mucha tecnología apropiada), G. Arroyo afirma que "En verdad la nueva biotecnología no obra por arte de magia ni trae necesariamente grandes beneficios. Su transferencia indiscriminada y bajo control de los intereses trasnacionales del Norte, contradictorios a menudo con los del Sur, podría acarrear muchas consecuencias negativas y aumentar la dependencia de los segundos respecto de los primeros y bloquear así aún más su desarrollo". ${ }^{30}$ Por otra parte también habría que tomar en cuenta que no sólo se trata de "cambiar" para utilizar tecnología apropiada sino además de cambiar para que esa tecnología produzca "bienes apropiados": es decir, que las técnicas apropiadas pueden estar orientadas a producir los mismos bienes, ya "apropiados" por la lógica de acumulación de las empresas transnacionales y no por la lógica e intereses de un proyecto nacional propio.

A continuación realizaremos una sintesis de las principales ideas expuestas por algunos representantes de las TDP.

- En primer lugar encontramos a C. Moser, el cual partiendo de una crítica de las teorías o políticas tradicionales sobre la pobreza ubana y el desempleo llega a postular la necesidad de un nuevo enfoque sobre dicha problemática del subdesarrollo. ${ }^{30}$ En tal enfoque juega un papel esencial el "descubrimiento" del sector informal como una realidad permanente y no como una situación transitoria (como una fase del paso de la sociedad tradicional a la moderna).

Senalemos que los estudios e informes de la OIT sobre Colombia, Sri Lanka y especialmente sobre Kenia (en 1964), tendientes a formular políticas de empleo, sirvieron de base para ese descubrimiento del sector informal y de su carácter estructural y no transitorio.

Los planteamientos de Moser pueden exponerse de la siguiente manera: 1) Una de las principales causas y manifestación del subdesarrollo es el desempleo permanente y creciente. 2) Por tanto hay que buscar

técnica debe servirle, es decir concebida en función de objetivos económicos y sociales". Rosier. Op. Cit. Pág. 129.

38. ARROYO, Gonzalo. La biotecnologia y el análisis de las cadenas o sistemas agroalimentarios y agroindustriales." Boletín de Ciencias Económicas y Sociales. UCA, Marzo/Abril 87, San Salvador. Pag. 118.

39. MOSER, Carolina. Informal Sector or Petty Commodity Production: Dualism of Dependance in Urban Development? Revista Word Development No. 910. 1978. Oxford. Gran Bretaña. Págs. 1041-1064. 
nuevas teorias/políticas para enfocar/solucionar el problema del empleo en el Tercer Mundo. 3) Un nuevo enfoque solución pasa por el análisis/ potenciación del sector informal. d) La potenciación del sector informal es básica para resolver el problema de desempleo. Hay pues que actuar sobre dichas potencialidades: 3.1. El sector informal es abastecedor importante de medios de subsistencia para las poblaciones de bajos ingresos (además quita peso al proceso de SM). 3.2 El sector informal representa una demanda significativa para los productos de origen agrario/ campesino. 3.3. Sus actividades laborales son intensivas en trabajo y pueden fundamentar la expansión de la industrialización (como pasa con las "economias de subcontratación" en Taiwan y Corea del Sur). En definitiva, el sector informal es y debe ser funcional al proceso de acumulación del capital, convirtiéndose asi en expresión de la funcionalidad del modo de producción mercantil simple al modo de producción capitalista.

Nos parece que los planteamientos de Moser no contienen un cuestionamiento del sistema capitalista como tal, ni mete en cuestión al contenido de su proceso de modernización/industrialización. Al contrario, expone claramente que frente a la anterior posibilidad de cambio por ruptura se opone una via adecuada y viable de transformaciones graduales en el marco de la modernización, en la que la reorientación del sector informal juega un rol de primer orden.

- En segundo lugar resaltemos las estratégias de Redistribución con Crecimiento. Holis Chenery y Montek Ahluwaliato colocaban como punto medular del desarrollo la posibilidad de hacer compatible el crecimiento con una equitativa distribución de los ingresos.

En sus análisis los autores afirman que el problema de la distribución de los ingresos no se reduce, como lo hacia el modelo de Kaldor-Robinson, a la simple puesta en relación de salarios y beneficios en general. Habria que ser más concretos y cuidadosos ya que la realidad es más compleja: hay diferentes relaciones de salarios y beneficios entre los distintos sectores, diferentes salarios entre y dentro de los sectores, y desiguales capacidades de ahorro y de acumulación. En consecuencia el crecimiento conlleva una compleja distribución del ingreso y de esto se deriva la exigencia de precisar las políticas redistributivas. Para Chenery y Ahluwalia la mejor manera de impulsar el desarrollo y compatibilizar el crecimiento con una equitativa distribución de ingresos es apoyando los sectores medios y pobres no asalariados, los cuales disponen de una mayor dinámica en su capacidad de ahorro y acumulación

40. Chenery y AHLUWAlia. Op. Cit. 
que la que tienen las grandes empresas. No estan muy de acuerdo entonces en las estratégias que priorizan el aumento de los grandes capitales como la mejor vía para incrementar el empleo y favorecer una adecuada distribución de ingresos.

La noción del desarrollo de la que es portadora esta estratégia no trasciende los limites de las TDM. O sea que parecidas conclusiones se pueden extraer respecto a la "funcionalidad" de este tipo de planteamientos con la dinámica de la acumulación del capital, tal como lo hicimos con las ideas de Moser.

- Otras teorias del desarrollo pragmático localizan como causa central del subdesarrollo el uso de tecnologías inapropiadas. Los análisis de Stewaro" sostienen que el uso de tecnologias producidas en los paises industrializados y creadas para mercados y fines acordes a las caracteristicas de los mismos, traen consecuencias negativas cuando son trasladadas a los paises del Tercer Mundo. Dentro de algunas de estas consecuencias se mencionan: la elevación de los costos de producción y/o del aumento de la capacidad productiva ociosa (pérdida de la eficacia del capital cuando la tecnologia que incorpora es desplegada en mercados estrechos y heterogéneos); incremento de desigualdades sociales y sectoriales (frente a la concentración de la tecnologia en las empresas o sectores con uso intensivo del capital); la dependencia administrativa (de cara a los requerimientos de importación de directores y/ o personal especializado); producción de "bienes inapropiados" (por el condicionamiento que la calidad de los bienes tienen respecto al tipo de tecnología empleada).

Hay que reconocer los aportes de las ideas de Steward en la medida que incursionan en temas que no parecen esenciales a tomar en cuenta en una concepción diferente del desarrollo: 1) La tecnologia apropiada hace incapié no sólo a su "adaptación técnica" a los mercados y/o al medio ambiente de los paises subdesarrollados sino también a las relaciones de dominio que determinan una elección técnica dentro de varias posibles (la producción de masas que se impone a otras formas más "flexibles" de producción). ${ }^{42}$

41. STEWARD, F. Technology and Underdevelopment. Macmilln. Capítulo III. Gran Bretaña. 1977.

42. Sobre este punto es interesante el estudio que hacen Charles Sabel y Jonathan Zeitlin sobre la imposición histórica de una posibilidad tecnológica (la combinación de maquinaria especializada en una sola tarea y trabajo no calificado para producir bienes standard) sobre otras técnicas posibles, dentro de las que se mencionan las técnicas más artesanales basadas en una especializacion flexible. Estas fueron significativas en determinadas re- 
2. La búsqueda de nuevos "senderos tecnológicos" (Sabel y Zeitlin. Op. Cit.) que desmistifiquen la omnipotencia dada a la división del trabajo y a la especialización como únicos factores de progreso. 3) El logro de un nuevo circuito de bienes, no determinado por el circuito de mercancias valorizables por el mercado internacional, cuyos controles y calidades respondan a la construcción de un proyecto nacional apropiado y apropiable por las mayorias locales.

El no considerar esos contenidos del desarrollo podria llevar a convertir la búsqueda/aplicación de la tecnología apropiada en una simple búsqueda de la funcionalidad de la misma respecto a las necesidades de modificación del funcionamiento del capital, tal como sucedia con las estratégias precedentes.

-Finalmente, aparecen aquellas estratégias de desarrollo en torno de la satisfacción de las necesidades básicas. Acá encontramos algunos autores/ideas que se alejan de la TDM y que podemos incluirlas más dentro de un grupo de teorias alternativas (teorias del desarrollo integrado, del desarrollo endógeno, del eco-desarrollo, etc). Pero dado que éstas son contempladas en el próximo apartado nos limitamos a las TDM que se inclinan por el tema de las "basic needs".

La importancia que adquieren esas estratégias del desarrollo, sobre todo al interior de los organismos internacionales, está en relación con una realidad alarmante y evidente: en 1980, reconocian los expertos del Banco Mundial, cerca de 800 millones de personas del planeta se encontraban en estado de "pobreza absoluta", es decir un tercio de la población del mundo. ${ }^{43}$

Un autor que "lleva lejos" los planteamientos de la estratégia basada en la satisfacción de las necesidades básicas es Paul Streeten. En un artículo publicado en 1978 sostiene que en la situación del mundo actual

giones industriales en el siglo XIX. (Lyón, Alsacia, Philadelfia son objeto de estudio por los autores). SABEL, Charles y ZEITLIN, Jonathan. Historical alternatives to mass production: politics, markets and technology in nineteencentury industrialisation. Revista Past and Present. No. 108. Londres 1985. Otro artículo recomendable al respecto es uno de J. Ph. Peemans que destaca el rol del artesano en la Francia del Siglo XIX y el uso de técnicas "dulces o flexiones" frente a la Revolución Inglesa, concentrando la tecnología moderna en unos pocos sectores (textil, siderurgia, minería) y con técnicas rígidas que abrlan el camino a la producción de masas, PEEMANS, Jean Philippe. Revolutions industrielles, modernisation et développement. Rapport CMID. Institut Supérieur de Philosophie. Université Catholique de Louvain. Bélgica. 1986.

43. Tomado de ROSIER y DOCKES. Op. Cit. Pág. 260. 
hay que colocar al hombre y sus necesidades en el centro del desarro$110 .{ }^{44}$ La satisfacción de las necosidades básicas y la eliminación de la pobreza, a nivel económico, dependen del valor de los blenes y servicios que los pobres producen y/o venden, por to que la solución de tal problema de desarrollo pasa por la exigencia de aumentar la demanda y la productividad dentro de los sectores populares. El autor reconoce sin embargo que estas medidas no son nuevas y ya han sido intentadas, como por ejemplo ciertas políticas redistributivas promovidas por el Ban$\infty$ Mundial. Propone por tanto otra serie de medidas para operativizar y hacer efectiva una verdadera estrategia con base en los "basic needs". Un elemento novedoso de ello parte del senalamiento de que una de las causas que han limitado las políticas de erradicción de la pobreza ha sido su excesivo énfasis en la eliminación de la misma, y no tomar en cuenta el hecho de que también se trata de proveer al ser humano de todas las condiciones para desarrollar su potencial, incluso el "no físico". Esto lleva a su vez a la formulación de importantes transformaciones, a tal punto de plantear el requerimiento de la participación local, del acceso a parcelas de poder por parte de grupos sociales diversos (entre ellos los más marginados), mayores libertades políticas, etc.

Sin embargo nos da la impresión que tales ideas "no van lejos" en la medida que permanecen dentro del marco de la TDM; esto en cuanto no se plantean el cómo son satisfechas las necesidades básicas, con qué tipo de bienes, con qué objetivos. Lo cual deja una serie de "vacios" que normalmente son rellenados por una visión fucional del proceso de acumulación del capital y por una concepción industrializante del desarrollo. De tal suerte que la satisfacción de las necesidades básicas a niveles físicos significa nutrir al pobre para que pueda producir mejor los bienes de la modernización, normalmente extrano al desarrollo de sus potencialidades como ser humano. Es más aún, la satisfacción de las necesidades no materiales (participación local, acceso a "parcelitas" del poder, etc.) puede ir en el sentido de mediatizar las inspiraciones políticas de los sectores populares y de integrarlos a las normas políticas establecidas. ${ }^{45}$ En este tipo de concepción del desarrollo se puede entonces "temer el resurgimiento de la concepción que precedia en el último siglo

44. STREETEN, Paul y BURKI, Shahid. Basic Needs. Some Issues. World Development No. 3 Londres. 1978. Págs. 411.421.

45. Ello no significa desvalorar las posibilidades y potencialidades de la participación local, o del acceso a parcelas de poder por determinados grupos sociales. No nos ubicamos en el dilema del todo o nada. Al contrario. Simplemente se trata de identificar el sentido que pueden adquirir tales aspectos de la participación o democratización. 
a las intervenciones de las sociedades filantrópicas donde la acción social consistia en asegurar a los pobres un minimo de subsistencia". ${ }^{46}$

\section{Hacla un concepto de desarrollo alternativo}

Ya en el transcurso de los comentarios y criticas hechas en el apartado anterior a las teorias del desarrollo (TC, TDM), hemos ido pertilando nuestra concepción del desarrollo.

Es menester pasar ahora a una presentación más explícita y amplia de la misma.

Como deciamos en la introducción a este documento, no se trata de elaborar o llegar a una nueva definición del desarrollo sino simplemente delimitar "un otro" concepto de desarrollo. La delimitación de dicho concepto podemos establecerla a nivel de los principios generales que deben regirlo, y por otro lado, a nivel de los requisitos mínimos que debe incorporar eso que entendemos por "un otro" desarrollo.

\section{Los principios generales}

Los principios o enunciados generales que rigen "un otro" desarrollo vamos a extraerlos partiendo de un método que podemos calificar de "definiciones negativas": es justamente negando las definiciones sobre el desarrollo dadas, explicita o implicitamente, por las Teorías del Desarrollo Predominantes que podemos enunciar lo que no es o no debe ser "un otro" desarrollo.

a. El desarrollo no se reduce al crecimiento, ni al crecimiento/acumulación sostenido y equilibrado. Desarrollarse no es equivalente de industrializarse, ni sinónimo de modernizacion. $Y$ de la misma forma que no se encierra sólo en los aspectos cuantitativos, tampoco lo hacen los factores de crecimiento, acumulación e industrialización que lo companan.

Con mucha mayor razón, un otro desarrollo no puede ser reducido a una forma de crecimiento y acumulación y a un tipo de industrialización..... normalmente presentados como universales y univocos por los paises del norte. Desarrollarse no es atarse a sólo una posibilidad histórica, muchas veces entre las menos adecuadas, sino irse abriendo al horizonte de las múltiples posibilidades.

b. El desarrollo no es un proceso que se da por etapas, ya previamente definidas, no es una línea a seguir, ni una secuencia de fases indus-

46. JACQUEMOT y RAFFINOT. Op. Cit. Pág. 52. 
triales a recorrer. Para llegar al socialismo no hace falta pasar por la previa maduración del capitalismo (como con contundencia histónica lo muestra la expansión preferencial del socialismo en los paises del Tercer Mundo), y la llegada al "socialismo" no garantiza su irreversibilidad al capitalismo (como sucede con las transformaciones actuales en los paises del Este de Europa). Para llegar al proceso de sustitución de exportaciones no es necesario pasar por el proceso de sustitución de importaciones; al contrario, como lo ilustran las experiencias de Japón, Corea del Sur y Taiwan, la sustitución de exportaciones puede servir como "prealable" de la profundización del proceso de sustitución de importaciones. No hay modelo único. Es más, que no hay modelo a seguir ya que no existe "un modelo" de desarrollo.

c. El desarrollo no aparece o se obtiene a partir de un punto de despegue (take-off de Rostow), es decir de un punto de ruptura con un pasado arcaico, atrasado y sin historia, y de un punto de partida hacia la modernidad y la "verdadera historia". Incluso en el caso de la industrialización europea del siglo $X \mid X$, sus supuestas "revoluciones industriales" no fueron producto de un "chispazo" provocado por la irrupción de la máquina de vapor sino de un largo y complejo proceso "preliminar de protoindustrialización, según un modelo donde industrias rurales y manufacturas dispersas han jugado un rol primordial". ${ }^{47}$

d. El desarrollo no es un resultado que emana de una "dinámica de arrastre" proveniente de unos cuantos polos modemos. La idea de que la concentración de los esfuerzos y recursos en unos pocos centros modemos irradiará posteriormente sus "efectos benéficos" sobre el resto de la economia, atrayendo a ésta hacia niveles superiores de desarrollo, es una idea que la reciente historia de los grandes complejos industriales se encarga de mostrar su falsedad. Sobre este punto Courlet y Judet anotarán que "los obstáculos a la difusión de los efectos industrializantes se refieren tanto a los paises desarrollados como a los paises en vias de desarrollo. Se sabe ahora que la creación de polos petroquimicos y siderúrgicos en el "Midi-Italien", lejos de haber impulsado un proceso de industrialización, ha provocado una crisis profunda en la red económica regional.... En cuanto a las Houillére du Dauphiné (cuenca minera de una región francesa. $\mathbf{N}$. del A.), su crecimiento después de la segunda guerra mundial, se ha ecompanado de un empobrecimiento progresivo de la red industrial local, sin abrir aparentemente posibilidades reales a la diver-

47. COURLET y JUDET, Op. Cit., p. 526. 
sificación". 40

e. El "subdesarrollo" no es producto de una falta de recursos o de condiciones económicas previas. No hay subdesarrollo porque hay pocas tierras fértiles, pocos capitales, escasos técnicos y débiles mercados. Al contrario, los suelos se agotan, los capitales no se encuentran, los pocos y buenos técnicos se fugan al extranjero y los mercados no se dinamizan precisamente porque hay subdesarrollo. Más que un problema técnico-económico, el problema del subdesarrollo es una problemática organizacional-institucional de orden político. EI subdesarrollo de las inmensas mayorias y las enormes "pérdidas sociales y económicas" que ello significa, es en buena medida consecuencia de una opción política: la opción tomada por y para el beneficio de unas minorias.

\section{Los requisitos minimos}

En primer lugar podemos dar cuenta de unos requisitos minimos que debe contener un otro desarrollo, retomando algunos aspectos positivos de las teorias del desarrollo antes expuestas.

a. Como lo indicarian de manera especial las Teorias del Crecimiento, el desarrollo debe distinguir entre crecimiento y acumulación y hacer compatible una dinámica sostenida y equilibrada entre ambos. O sea que el desarrollo debe contener aspectos cuantitativos minimos, una determinada y creciente cantidad de excedentes, cierta e importante capacidad de producción.

b. Como lo anotaban también tanto las teorias del crecimiento como las TDM, el aspecto tecnológico desempena un papel significativo en el desarrollo. En efecto, éste implica producir más y mejor en el menor tiempo posible (aunque no necesariamente).

c. Es conveniente, aunque no imperativo, tomar en consideración la variable demográfica, y acompanar el desarrollo con programs adecuados de regulación del crecimiento de la población. Pero esto debe darse bajo una óptica que perciba a la población y/o masa de trabajadores como factores de potenciación y de impulso al desarrollo. Las densidades 0 incrementos demográficos no deben ser vistos como una carga para el desarrollo sino como la principal riqueza de que se dispone para salir del "subdesarrollo". Ahi estan muchas experiencias de desarrollo rural en China para dar buena muestra de ello.

48. Ibid, P. $\mathbf{5 3 0 .}$ 
d. Un otro desarrollo es sinónimo de integridad. Ello quiere decir que los hechos económicos o sociales poseen un carácter estructural y multifacético. Estructural en cuanto cada fenómeno no se da o existe aisladamente sino que forma parte de un sistema general. Asi, en la TD, el subdesarrollo no es sólo un fenómeno interno sino también y sobre todo, externo, y por otro lado, la dinámica de la estructura industrial está ligada a la buena marcha de la estructura agraria.

Pero al mismo tiempo, el subdesarrollo no es solamente un problema estructural económico-técnico (como lo presenta la primera versión de la TD) sino un fenómeno de muchas facetas, que integran al unisono aspectos políticos culturales, ideológicos, etc., estrechamente vinculados entre sl (como exponia la segunda versión de la TD, y más en particular las que hacian referencia a la articulación de modos de producción).

Otros requisitos mínimos completan y redefinen los anteriores, y surgen de las nuevas concepciones del desarrollo, ya sea que se denominen bajo el nombre de Ecodesarrollo, desarrollo Endógeno, Desarrollo Alternativo, etc. ${ }^{49}$

a. Es cierto que es necesario un crecimiento/acumulación sostenido y equilibrado, pero la cuestión fundamental es saber ¿HACIA DONDE DIRIGIR ESOS PROCESOS? ¿QUE ES LO QUE SE PRODUCE?. Por tanto un otro desarrollo destaca en prioridad los tipos de bienes que se producen, y concibe los resultados de la producción más en términos de valores de uso que de valores de cambio. En tal sentido, la respuesta que daria otra concepción del desarrollo a las interrogantes anteriores es clara: el crecimiento y la acumulacion deben orientarse primordialmente a la satisfacción de las necesidades básicas de las mayorias y a mejorar la calidad de sus condiciones de vida.

Tomando en cuenta lo anterior, un proceso de desarrollo debe definir, al menos, tres tipos de bienes y servicios: los bienes y servicios básicos, los no básicos y los estériles y/o nocivos. Se trata de una clasificación que parte de otra semejante presentada por I. Sachs. ${ }^{50}$ Este distingue tres grupos de bienes y servicios: 1. Los bienes y servicios

49. Estas teorlas encuentran un fundamento en el informe del llamado Proyecto Dag Hammarskjöld de 1975 sobre el Desarrollo y Cooperación Internacional, y títulado "Qué hacer: otro desarrollo". Según Marc Nertin, dicho informe caracterizarla "otro desarrollo" como: orientado acorde a las necesidades, endógeno, autosuficiente, ecológicamente solvente y basado en transformaciones estructurales. Ver VARIOS AUTORES, Hacia otro desarrollo: enfoques y estrategias, Siglo XXI Editores, México, 1978, páginas introductorias.

50. SACHS Ignacy, op. Cit. 
esenciales, que corresponden a las necesidades socialmente prioritarias. 2. Los bienes y servicios no esenciales. 3. Los armamentos, más lo que dicho autor denomina "la parte estéril del PNB" y que hace mención a todos aquellos gastos o inversiones que no agregan nada al bienestar y que más bien sirven para reponer o sufragar los gastos ocasionados por los "males" de la modernización: bienes y servicios destinados a la descontaminación del ambiente, los gastos del transporte "contrainte" ocasionados por la urbanización desordenada que aleja cada vez más los centros de trabajo de los de vivienda, los gastos utilizados en prácticas de salud y cuidado a las victimas de accidentes en las autopistas, etc.

Para nosotros tendriamos lo siguiente: 1. Los bienes y servicios básicos, que corresponden a aquéllos directamente implicados en la satisfacción de las necesidades básicas de las mayorias. Entre los cuales podemos resaltar: la producción de cereales, verduras, frutas, carne, leche y derivados, pescados, etc., que proporcionan una "dieta básica", asi como la adquisición de la maquinaria, equipos e instalaciones que hacen posible y mejorable dicha producción alimenticia; los diferentes servicios (comerciales, financieros, energéticos, de transporte, etc.) que estimulan esas producciones y facilitan su accesibilidad y conservación; los procesos educativos e investigativos que proporcionan o buscan los instrumentos teóricos y técnicos adecuados para hacer dicha producción realizable y más calificada. De la misma forma también se incluirian todas aquellas maquinarias, equipamientos, instalaciones, servicios, procesos educativos y científico-técnicos, etc. que concreticen y promuevan la calificada producción, conservación y accesibilidad de otros bienes y servicios básicos como los textiles, prendas de vestir, calzado, medicamentos, viviendas, la movilización colectiva (autobuses, trenes), la preparación adecuada y sana de los alimentos, los cuidados médicos,la educación, la recreación y esparcimiento, los productos higiénicos, etc. 2. Los bienes y servicios no básicos, que si pueden incrementar el bienestar de la población pero que no satisfacen las necesidades socialmente básicas. Entre algunos de ellos podemos mencionar: los automóviles, en especial los de lujo, asi como todos los servicio que su producción y mantenimiento acompanan y las producciones anexas que se ven implicadas (repuestos, llantas, aceites, pinturas, etc.), los productos de belleza, las motos recreativas, los gastos y artículos publicitarios, las bebidas alcohólicas, perfumeria, productos decorativos, servicios de masaje y peinado, ciertos electrodomésticos, joyeria, productos alimenticios "exóticos", etc. 3. Además de los bienes y servicios estériles ya senalados por Sachs, y que se refieren más a la realidad de los paises industrializados, añadamos otros más pertinentes a la realidad salvadorena: gastos en armas, en máquinas, equipos e instalaciones destinadas a la 
guerra interna o a la represión; gastos diversos destinados a reparar los males de guerra (reposión o reparación de la infraestructura destruida, hospitales militares y gastos médicos por los heridos o muertos en combate, reposición o reparación de cosechas bombardeadas, etc.); inversiones adicionales de irrigación y/o reparación de suelos debido a la erosión de la tierra y sus efectos sobre el abastecimiento de agua; gastos médicos ligados a enfermedades 0 accidentes provenientes de, 0 estimulados por, la mala calidad y falta de control técnico del transporte y/o de las deficiencias en la senalización y estado de las carreteras; tiempo y dinero empleado en trámites burocráticos innecesarios, etc. ${ }^{51}$

A la noción de bienes y servicios estériles debemos añadir el calificativo de nocivos. O sea que hay que incluir en este tercer grupo todos aquellos bienes y servicios, inclusive los más básicos, que son o pueden ser nocivos para la salud física y mental de las personas, la salud física de los animales (sobre todo los de consumo humano) y para las relaciones del ser humano con la naturaleza. Asi para el caso, un bien básico como el medicamento puede ser danino para la salud fisica y mental, como lo vienen demostrando las numerosas prohibiciones de que son objeto muchos medicamentos. De forma semejante, la expansión especializada del monocultivo, incluso en el caso de un cereal, puede provocar serios danos al ecosistema; asi como los autobuses colectivos en estado de deterioro se convierten en una "amenaza rodante" para todo los ciudadanos.

En resumen, otra concepción del desarrollo basada en una estratégia de satisfacción de necesidades básicas y mejora de la calidad de vida debe contemplar un crecimiento/acumulación sostenido y equilibrado y una utilización del excedente resultante que tiendan a la maximización de la producción y consumo calificado de los bienes y servicios básicos y a la minimización de los estériles/nocivos.

51. Maticemos que esa división entre lo básico y lo no básico es flexible y acorde a las particularidades y necesidades de cada pais, región, localidad, etc. Lo que es básico en un tiempo y espacio determinado puede no serlo en otro. Sin embargo, hay que precisar que tal flexibilidad tiene un limite: es posible que un automóvil o un reloj sea básico para una persona en determinadas circunstancias, pero según este argumento y lógica, y dada la multiplicidad de situaciones individuales, todos los bienes y servicios podrlan ser básicos y no básicos al mismo tiempo. El limite viene dado por el hecho de que no se trata de circunstancias individuales sino de "situaciones colectivas", es decir lo básico hace mención a las necesidades prioritarias de la mayoría de la población y no a unos individuos o unos grupos sociales minoritarios. 
No cabe duda que la puesta en marcha de tal estratégia conlleva una profunda transformación a nivel de la distribución de los recursos e ingresos. Dentro de un esquema de mercado, una forma fundamental de garantizar la accesibilidad a los nuevos bienes y servicios producidos es por medio de la elevación permanente de ingresos de las mayorias y/o por medio del desarrollo del sector no mercantil. $Y$ una manera de garantizar esta elevación y desarrollo en forma continuada es a través de un cambio sensible en la asignación y propiedad de los recursos.

b. Por otra parte, el desarrollo no sólo se pregunta por el contenido que asumen los bienes y servicios (qué se produce y en qué se utiliza el excedente generado) sino también por EL COMO Y BAJO CUALES CONDICIONES SE PRODUCEN. Esto nos remite a las formas de extracción del excedente, a las maneras de como se crece y acumula. Sobre el tema proponemos otros requisitos mínimos que debe integrar una noción diferente del desarrollo:

b.1 No es suficiente reconocer la importancia de la técnica y sus pertiles cuantitativos. Es imprescindible también comprender la trascendencia del tipo de técnica elegida y puesta en obra, es decir sus pertiles cualitativos. Por tanto, una nueva visión del desarrollo escoge y concreta sus opciones técnicas sobre parámetros que no se limitan al simple criterio de la productividad, medida numericamente en términos de producto por unidad. Las nuevas opciones tecnológicas deben ser sensibles a nuevos indicadores: a los efectos sobre el medio ambiente y la salud física y mental de los trabajadores, a los grados de dependencia y a las posibilidades de crear un proyecto nacional, a las incidencias sobre la creatividad humana, al "grado de humanizacion" de los procesos de trabajo y a la gestación de formas solidarias de organización social, a la calidad de bienes y servicios producidos, etc.

b.2 Para lograr un desarrollo diferente no basta tampoco considerar la variable demográfica y otorgarle al incremento de la fuerza de trabajo un sentido positivo. Es preciso desprenderse del carácter funcionalista dado a su utilización como factor productivo. Es cierto que el trabajo, o más concretamente los trabajadores, es una de las principales riquezas con que cuentan los paises del Tercer Mundo. Pero no es una fuente que deba estar en función y disposición del enriquecimiento de aquellos que normalmente la controlan, sino de la expansión de las capacidades y potencialidades de los mismos trabajadores. Los excedentes del trabajo, expresado en personas o productos, no deben tender a consolidar un proceso de acumulación ajeno a las mayorías sino favorecer mejores estilos de vida para las mismas, y para garantizar que no hayan "estómagos vacios" y "cerebros desnutridos" de imaginación y esperanza. 
Como ya muchos to han afirmado con insistencia, el ser humano, y especialmente las mayorias desposeidas, no es objeto sino ante todo sujeto del desarrollo.

Y si el ser humano es el centro del desarrollo como tan comúnmente se predica, entonces hay que llevar este precepto hasta sus últimas consecuencias, sobre todo en lo que compete a las relaciones que guardan las personas entre si. Lo cual, traducido en el terreno laboral, va más allá de las meras reivindicaciones salariales, de las demandas por mayores puestos de trabajo y de cobertura de la seguridad social, de las peticiones por la modificación de los rígidos contratos de trabajo. Sin negar la importancia y validez de éstas, una otra via de desarrollo debe también sentar bases para otras reivindicaciones en torno a: el acceso y control equitativo de los recursos productivos y monetarios; la conformación de unas relaciones de producción colectivas y solidarias; una participación efectiva de los trabajadores en las decisiones tomadas al seno de las empresas, sobre todo de las que atañen a las condiciones de trabajo, tipo de técnica utilizada y calidad de los bienes producidos; una participación también eficaz de los trabajadores fuera de los centros de trabajo, como ciudadanos y consumidores que son, en las decisiones tomadas y elaboradas alrededor de la actividad económica, de preferencia en aquellas que afectan directamente la satisfacción de sus necesidades básicas y la calidad de sus formas de vida. De esto último surge la necesidad de que la dinámica del desarrollo promueva las asociaciones de defensa del consumidor, asociaciones de vecinos, organizaciones de barrios y colonias marginales, de juntas comunales de vigilancia médica y sanitaria, de movimientos pacifistas y ecologistas, juntas comunales de promoción y defensa de servicios públicos y/o infraestructura colectiva.

b.3. Punto obligado de referencia de otro desarrollo es el Ecodesarrollo y su insistencia en el "respeto" que deben tener las actividades humanas hacia la naturaleza. En efecto, toda actividad humana está intimamente ligada a la naturaleza que to circunda, y muchas actividades económicas, en particular las agropecuarias, afectan el equilibrio del ecosistema: "Con la agricultura, aparecida hace diez mil anos solamente, el hombre interviene sistemáticamente en los procesos naturales, en las cadenas alimentarias para aumentar y regular la cantidad de energia utilizable por él, seleccionando los seres biológicos y aplicándole las técnicas cada vez más elaboradas, es decir creando los desequilibrios en los ecosistemas. Un sistema agricola dado introduce en efecto un desequilibrio en un sistema ecológico determinado y no puede mante- 
nerse por un largo periodo más que si un nuevo equilibrio aparece".52

Respetar la naturaleza es entonces escoger técnicas, procesos de trabajo, sustancias, etc., que minimizen los desequilibrios provocados en el ecosistema y maximizen las posibilidades y condiciones de su reequilibrio. Pero las nociones predominantes del desarrollo y las actividades humanas que de ellas se derivan hacen exactamente to contrario. Por un lado, tienden a maximizar los desequilibros: no sólo a nivel local o regional (polución urbana, afectación de los micro-climas, deforestación y merma del abastecimiento de agua, etc.) sino también a escala continental (como la desertificación del Africa Sub-Sahariana), y más grave aún, a la escala planetaria (agotamiento de los recursos naturales no renovables, reducción alarmante de la capa protectora de azono en la atmósfera, "efecto invernadero"). Por otro lado, tales actividades tienden a minimizar las posibilidades de reestablecer los equilibros danados: ello en vista que los costos económicos y sociales en que se traducen y expresan los desequilibrios ecológicos causados por la modernidad, no son considerados como costos internos a las empresas sino como "extemalidades" de la misma. En consecuencia, los gastos de reestablecimiento de los desequilibrios no corren por cuenta de aquellos que los producen; como mínimo, caen a cargo de los presupuestos del Estado.

Respetando los equilibrios del ecosistema el desarrollo es una via solidaria con las futuras generaciones que habitarán el planeta. Desarrollarse no tiene por objetivo solamente la satifacción de las necesidades básicas y mejora de la calidad de vida de las poblaciones actuales, sino con una perspectiva a largo plazo, el garantizársela a las venideras.

c. Finalmente, poseer una visión integral del desarrollo lleva a interrogarse también por el "PARA QUIEN SE PRODUCE". Para responder a tan importante cuestión vamos a realizar una redefinición crítica de los requisitos al desarrollo que proponian algunas TDM.

c.1. Considerando el análisis del fenómeno de la dependencia podemos afirmar que desarrollarse implica adquirir mayores grados de independencia respecto a los paises centrales. Pero para el logro de esto no es suficiente el "interiorizar el proceso de acumulación y los excedentes" como los sostiene la TD. Es menester que esa interiorización se haga en base a un proyecto nacional propio y acorde a los intereses, cultura e historia de cada pueblo en cuestión. No se trata de interiorizar la acumulación para promover la gestación o consolidación de una burguesia nacional, ni de implementar una política de recuperación del excedente nacional y su utilización interna para producir los mismos tipos de bienes

52. ROSIER Bernad, op. Cit., p. 124. 
valorados por el circuito internacional de mercancias, controlado por las empresas transnacionales.

c.2. Ciertamente la visión integral de otro desarrollo percibe los fenómenos dentro de una red de interconexiones múltiples: los hechos no se dan aisladamente sino en el marco de una estructura y contienen al mismo tiempo varias dimensiones (históricas, económicas, culturales, etc.). Pero las articulaciones que se dan entre el modo de producción capitalista con los no capitalistas (P. P. Rey), entre la economia formal con la informal (Moser), entre la industria y la agricultura (teorias sobre el rol del agro en el desarrollo), asi como los múltiples aspectos (religiosos, políticos, económicos, ideológicos) que definen y determinan dichas interrelaciones, no son, y no deben ser, de carácter funcional. No se trata de hacer más funcional al agro para impulsar la industrialización, ni a la economia informal para mejor servir a la formalidad capitalista. Tampoco se pretende incorporar los análisis antropológicos al estudio del desarrollo para mejorar o adaptar la introducción de la modernidad en los modos de producción no capitalistas o para homogenizarlos con el capital. Una otra manera de ver el desarrollo no se cine a las relaciones funcionales; y cuando éstas tienen que ser consideradas, entonces puede otorgarles un sentido inverso al que tradicionalmente se le da: en ciertos momentos es más bien la industria la que debe estar en función del agro, y son las necesidades del desarrollo agrario las que determinan el tipo de técnica y bienes industriales, y no lo contrario.

Por tanto, un desarrollo diferente debe respetar la diversidad de las realidades socio-económicas: desarrollarse no es homogenizar en la modernidad todo aquello que no lo es sino saber aprovechar las riquezas y potencialidades que nacen de la puesta en contacto de las realidades heterogéneas. ¿Cuántas técnicas, cuántos valores culturales, cuántas formas adecuadas y sanas de producción, distribución, consumo y organización laboral han quedado enterradas en la historia en nombre de la universalidad y unilateralidad del desarrollo moderno? ¿Es que acaso las ancestrales y efectivas curas por medio de plantas medicinales dan prueba de inferioridad frente a las muchas veces nocivas "curas" practicadas por la industria farmacéutica? ¿Dónde quedaron tantos conocimientos históricamente acumulados que la modernidad suele guardar como "piezas de museo"? ¿Dónde han quedado los originales sistemas de rotación e irrigación de cultivos que hicieron florecer muchos pueblos indigenas de Latinoamérica, o los métodos casi gratuitos de alimentación porcina por medio de forrajes silvestres que solian utilizar siervos y/o campesinos de la Europa Central del Medioevo?

Frente a semejantes interrogantes habria que dejar en claro que una 
otra manera de desarrollarse no es un canto bucólico a la vuelta al pasado y/o al naturismo sino una mirada al futuro que sabe recoger los mejores y diversos paisajes del pasado.

c.3. Para la TD (la segunda versión en especial) los cambios en la estructura económica demandaban cambios en las estructuras políticas internas y exigian un nuevo orden económico internacional. Una seria y consistente política de redistribución de ingresos no era posible sin una reasignación equitativa de los recursos productivos, sobre todo de la tierra, y de profundos cambios en la propiedad y formas de tenencia. $Y$ esto sólo sería factible por la transformación de las relaciones de poder: es decir modificaciones que desplacen del poder justamente a las minorias que se mantienen en él gracias al control, administración y usufructo en la propiedad de dichos recursos (no importando que tal propiedad tenga un carácter privado, colectivo o estatal).

Pero desarrollarse no sólo requiere del desplazamiento de una clase minoritaria o de un grupo dirigente de los aparatos del poder y su sustitución por nuevas clases o grupos más cercanos o más sensibles a los intereses populares. Para mostrar la insuficiencia de tal requerimiento traigamos a cuenta las experiencias de burocratismo, corrupción, de falta de pluralismo y de reales ejercicios democráticos que se dieron o dan en muchos paises hasta hace poco denominados socialistas. No está exento de cierta razón el eslogan justificativo que manejan los defensores del capital y del libre mercado de que las revoluciones han servido para sustituir una dictadura por otra.

Por ello el acceso al poder, o a parcelas del mismo, por clases o grupos con sensibilidades y pretensiones populares es una condición necesaria pero no ciertamente suficiente para iniciar un verdadero proceso de desarrollo. Hay que recordar que la orientación de las estructuras económicas, sociales y políticas al servicio de los pueblos no es solamente un problema de acceso sino también, y ante todo, de participación y ejercicio democrático cotidiano de las mayorias.

Un desarrollo de otro tipo debe entonces sentar las condiciones socio-económicas e institucionales que permitan la participación libre y continuada de todos los sectores del pueblo a todos los niveles posibles. Esto significa, al menos: construir las bases para garantizar la participación de los trabajadores en la toma de decisiones de las empresas y en la elaboración de los planes sectoriales, regionales y nacionales; fomentar la participción de las personas, en tanto consumidores y sujetos del desarrollo, en la definición de los estilos locales o globales de desarrollo; promover a los ciudadanos y sus diferentes organizaciones en el ejercicio del poder político, y no reducir éste sólo a las prácticas 
electorales y a la simple formalidad representativa dentro de un hemiciclo parlamentario. En fin, se pretende el reforzamiento de la sociedad civil frente a la omnipotencia de la sociedad política por la via del ejercicio democrático cotidiano, y de la misma participación política de la sociedad civil. $Y$ poner en marcha un proyecto semejante es contribuir a que el acceso al poder por un grupo o clase determinada no se traduzca posteriormente en un alejamiento de los intereses de las mayorias y de los objetivos de un otro desarrollo.

Hasta aqui un primer esbozo general de lo que podría ser otra concepción del desarrollo de las sociedades. Como lo expusimos en la introducción, esperamos que este material de trabajo sina como base para una elaboración más precisa de lo que debería comprender el desarrollo de la sociedad salvadorena en la época de post-guerra. 